\title{
استخدام منهجية التحليل المكاني في تقييم الملائمة المكانية للتوسع الحضري لمدينة
} الكوت

م.م. أحمد عبد السلام حنش الجابري

كلية التخطيط العمراني

جامعة الكوفة
أ.د. كامل كاظم بشير الكناني

معهد التخطيط الحضري والاقليمي للاراسات العليا

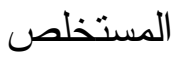

يهدف هذا البحث تقييم الملاءمة المكانية للتوسع الحضري لمدينة الكوت للفترة المستقبلية

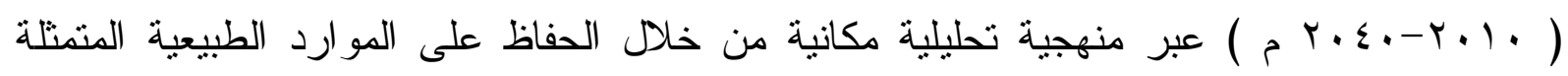

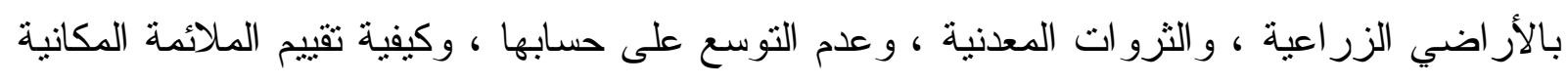

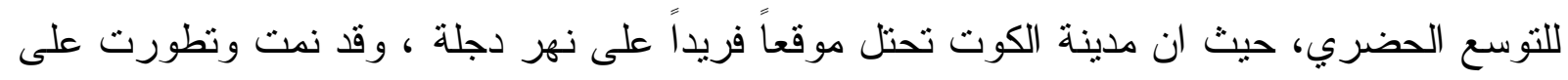

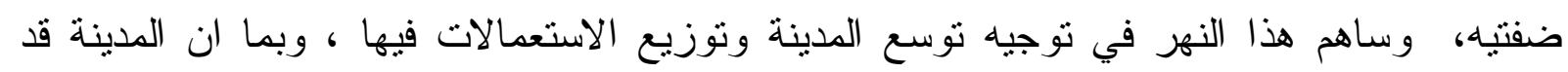

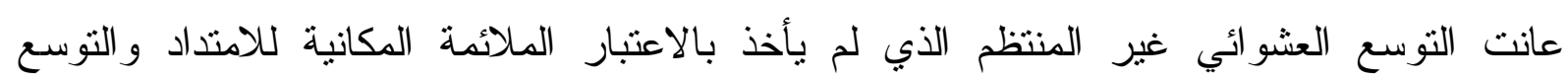

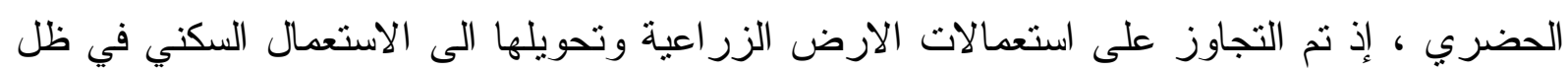

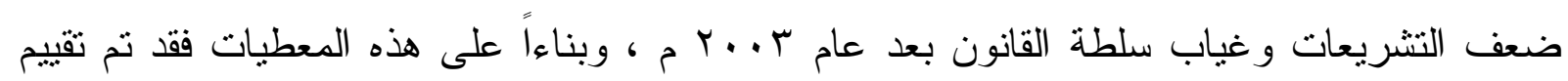

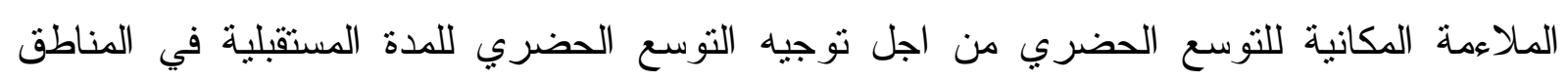
الاكثر ملاءمة من غير ها من خلال دراسة العو امل المؤثرة في التوسع الحضري لمدئه لمدينة الكوت وتحليل

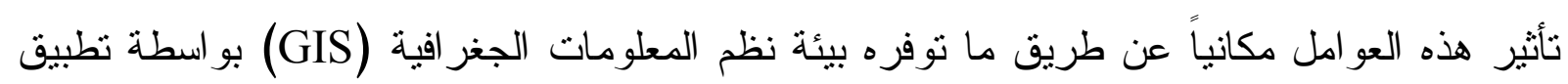

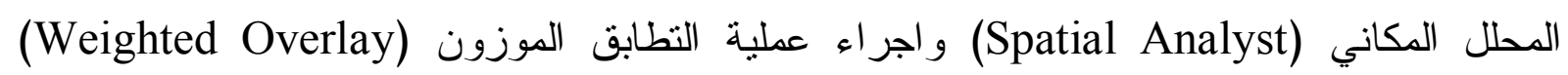

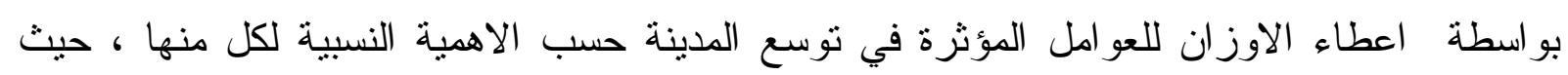

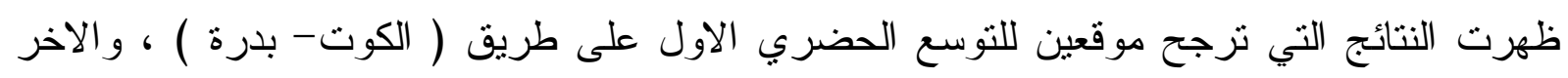

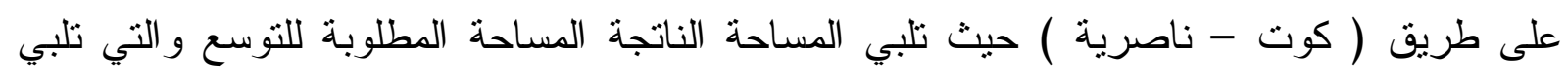
الاحتياجات كافة . 


\section{Abstract}

This research aimed evaluate of the spatial suitability for the urban expansion for the city of Kut for the years (2010-2040) through the spatial analytical methodology by reviewing the spatial analysis and urban expansion literatures and the ways of achieving sustainability by conserving the natural resources of agricultural land and mineral wealth and prevent expanding at their expense, and how to evaluate the spatial suitability for the urban expansion, . The research then approached the existing situation of Kut city occupies a unique location on the Tigris River where it was grown and developed on the river's banks, which contributed in guiding the city's expansion and its land use distribution, It has been shown through the study that the city suffered from random and irregular expansion, which did not take into account the spatial suitability for the urban expansion and extension, where new residential use expanded on the expense of the agricultural land due to the weak legislations and lack of rules of law after 2003, According to this situation spatial suitability for urban expansion was evaluated in order to guide future urban expansion till the target year (2040) in more suitable areas than others by studying the factors affecting the urban expansion of the city of Kut and analyze the spatial impact of these factors depending on the environment of geographic information system (GIS), and the application of the (Spatial Analyst). The process of weighted matching (Weighted Overlay) was done through giving weights to the factors affecting the expansion of the city according to the relative importance of each factor. The results apparently suggest the occurrence of two urban expansion sites. The first one is on the road (Kut - Badra), and the other one is on the road (Kut - Nasiriya), where these two suggested spaces meets the required area needed for expansion till the target year 2040.

مشكلة البحث:

تكمن مشكلة البحث في انه في كثير من الحالات يتم اختيار محاور التوسع للمخططات الاساسية

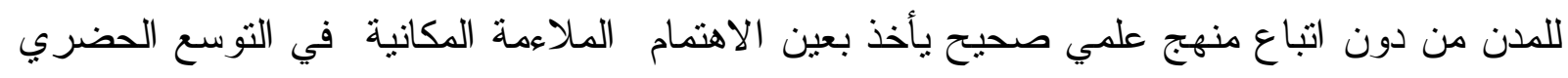

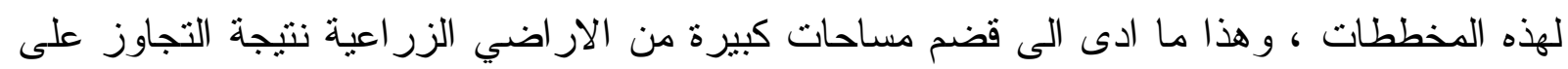

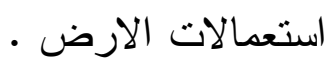
هدف البحث :

يتجسد هدف البحث في دراسة وتحليل مجالات التوسع الحضري للمخططات الاساسية و محاوره

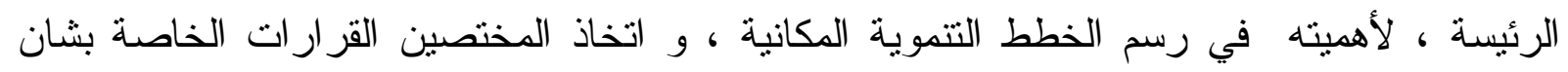
تطوير المدن العراقية وتجنيبها النمو العشوائي من خلال استخدام منهجية التحليل المكاني واستخدام 
التقنيات الحديثة التي نوفرها برمجيات نظم المعلومات الجغر افية الـ GIS عبر تطبيق المحلل المكاني

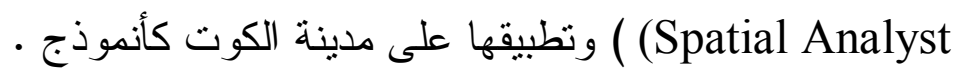
فرضبة البحث :

ان منهجية التحليل المكاني العمبة الدقيقة التي تأخذ أبرز العو امل الاقتصادية و العمرانية و البيئية

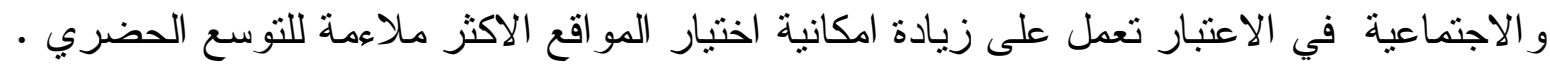

\section{منهجية البحث:}

تعتمد منهجية البحث على التحليل المكاني عبر منهج التحليل الوصفي من خلال نطبيق المُحلِّل

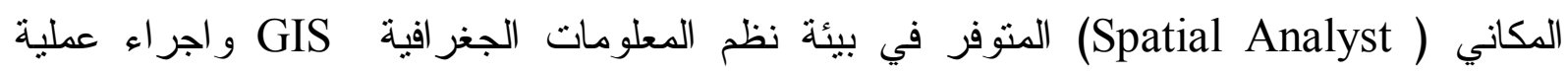
النطابق الموزون (Weighted Overlay) في تقييم الملاعمة المكانية .

\section{الحدود المكاتية والزماتية للبحث :}

تتجلى الحدود المكانية عن طريق تحليل الملاعمة المكانية للتوسع الحضري خارج الحدود البلدية

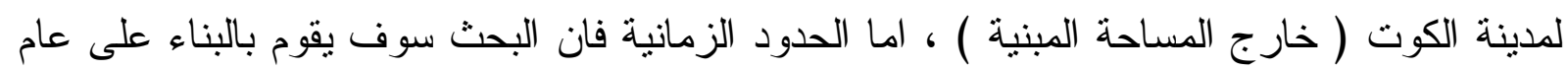

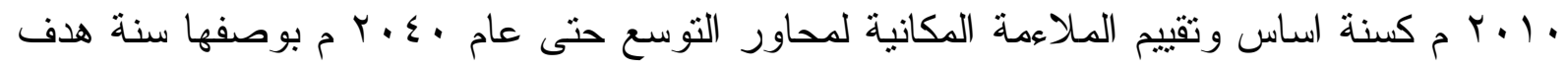

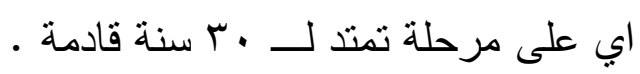

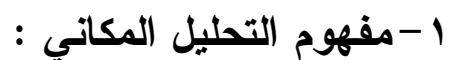

وهو اسلوب لقياس العلاقات المكانية بين الظواهر و بما يضمن تفسير العلاقات المكانية

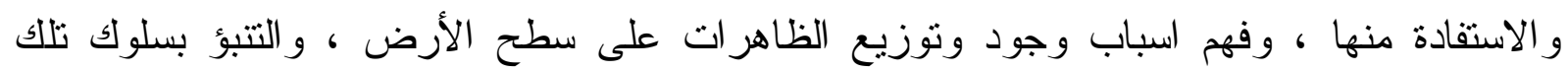

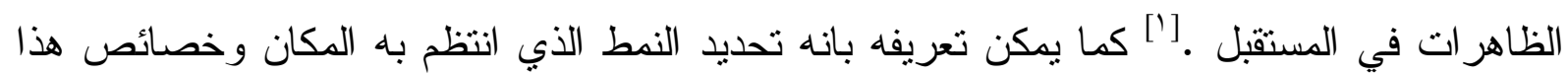

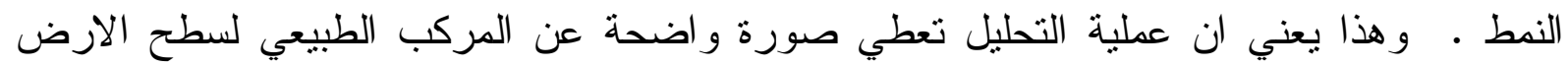
وخصائصها التي تهم الانسان ونشاطاته المختلفة مثل التضاريس والعمليات الجيومرفولوجية و الجيولوجية وكذللك خصائص الصخر ، و التربة ، و الماء ، و النبات الطبيعي ، و المو ارد المتو افرة فيه. 
و هذه جميعها يتم تمثيلها في خر ائط خاصة بتصنيف الارض تشكِّ مدخلات ضرورية لغرض تقييم الار اضي الريفية ومن ثم تحديد الاستعمالات المناسبة و المنلى لكل صنف من اصناف الارض . ["] و اما تقييم الاراضي الحضرية فان تقييمها يقوم على اسعار الار اضي الذي يختلف من منطقة لأخرى داخل المدينة بسبب تأثير مجمو عة من العو امل التي يمكن حصر ها في [ऍ] :

ا -الكثافة السكانية ـ r - الموقع وخصائصه الطبيعية و الاقتصادية ـ r- مقدار الضر ائب و الرسوم • ع- درجة الافضلية و المنافسة و الاستثمار ـ 0- مو اقع المؤسسات العامة ـ ؟- سعة الثو ارع وشبكات الطرق وسهولة الوصول • V- نوع الاستعمال السائد وانواع الاستعمالات المجاورة . یطوبوغر افية الارض ن

\section{ب- منهجية التحليل المكاني :}

تتردد كلمة المنهجية في كثير من فروع العلوم المختلفة ، بما فيها علم التخطيط الحضري • ولما كانت المعاني و المصطلحات التخطيطية تختلط بين المر احل و المنهجية ، لزم تقديم توضيح دقيق لهذا

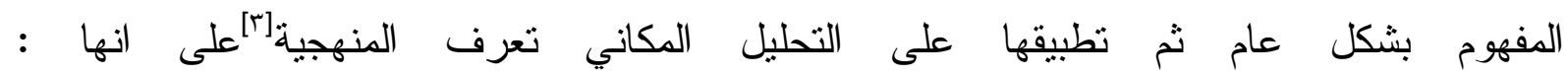
"مجموعة من الاسس و التطبيقات و الاساليب لجمع البيانات وتحليلها وعرضها ، تستخدم لتحقيق اهداف مشروع ما سو اء اكان على المدى القصير ام البعيد بشكل متماسك ومتجانس ومسؤول وقابل للتكر ار . وتحتوي المنهجية على مجموعة من المعايير لتقييم كل مرحلة من مر احل العمل . "

إن منهجية التحليل المكاني تعرف على انها منهجية تحليلية لدر اسة قدرة موقع ما لاعم نشاط محدد ، كما انها تعمل على در اسة العلاقات بين الخصائص الجغر افية للعناصر الطبيعية لموقع معين للتعرف على الميز ات الكامنة به . [؛] ان هذه العلاقات قائمة على ارتباط كل مظهر على سطح الارض بغيره

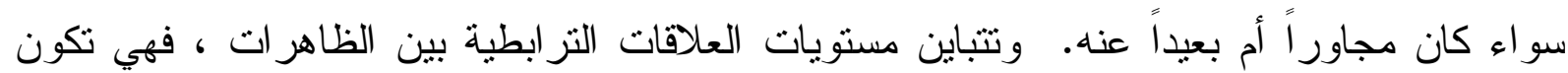
قوية او ضعيفة ، طردية او عكسية ، شاملة او محلية ، مؤقتة او دائمة ، تبعاً لتباين مكوناتها وخصائص عناصر ها ، فالتغير الذي ينتابها هو محصلة التغير في ظو اهر مكانية وزمانية ـ ويؤثز هذا

وأنغيم ،محمد عثمان \& ماجد ابو زنط ،"التتمية المستدامة ـ فلسفتها واساليب تخطيطيها وادوات قياسها " ، دار صفاء للطباعة والنشر

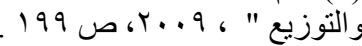

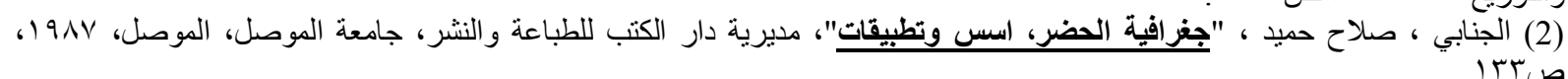

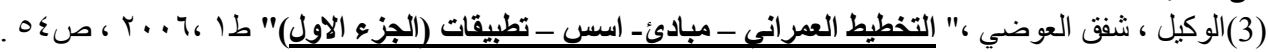

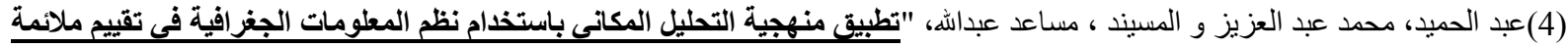

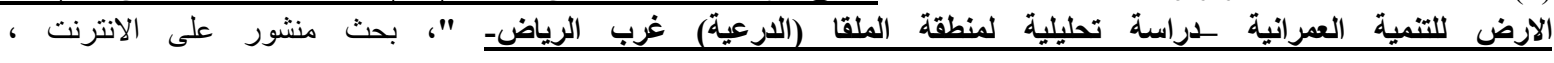
rgeography.com/vb/t8137.html 
التغير في غير ها من الظاهر ات المرتبطة معها فتتغير هي الاخرى ، وتصبح الظاهرات في المكان متغيرة باستمر ار بمرور الزمن وتغير قيمة المكان •

و على المُخطُّ ان يشعر بالتغير الذي انتاب الظاهرة بقوة الملاحظة الميدانية ، او بتحويل خصائص الظاهرة الى قيم كمية يمكن استعمالها احصائياً في قياس العلاقة الارتباطية ، او باستعمال خصائصها احصائياً في قياس العلاقات الارتباطية ، او باستعمال خصائصها المكانية من الموقع ، و الشكل ، و المساحة ، و الابعاد ، و الحدود ، و المحيط ، و الامتداد ، وما يحيط بها من ظاهر ات اخرى لكل منها خصائصها المكانية المستقلة في تقييم التغير في خصائص الظاهرات ، فالظاهرة لا تتغير منفردة ولكنها محصلة التغير الذي ينتاب الظواهر الاخرى ، كما انها تؤثز بدورها في الظواهر الاخرى . فالعلاقات المكانية علاقات غير منعزلة بل هي علاقات منتابكة ومعقدة ، تزتبط بمجموعة كبيرة من القياسات المكانية التي تفسر سلوك العلاقات ، ومستوى قوتها ، ومدى ارتباطها بظاهر ات مجاورة او بعيدة عنها ، ومدى ارتباطها بالتنظيم المكاني للفعاليات الموجودة . [1]

وتأتي الفائدة من استخدام منهجية التحليل المكاني من كونه يعمل على تقييم درجة الملاءمة و القابلية لموقع ما للتوسع الحضري • كما ان له قدرة على استتاج التتبؤات ، حيث يقوم بإبراز امكانات الموقع و ابرز ظو اهره المكانية من حيث مكانها الجغر افي المعرف بإحداثيات مكانية محددة

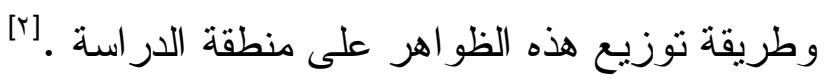

إن تأسيس وتطوير منهجية التحليل المكاني لتحقيق التوسع الحضري المستدام، والأي يلبي احتياجات الحاضر من دون المساس باحتياجات الاجيال المقبلة ويقدرته على الوفاء باحتياجاتها عن طريق العمل على تجنب العشوائية في توزيع استعمالات الارض والمحافظة على الاراضي المحيطة بالمدينة ولاسيما الاراضي الزراعية والار اضي التي تضم الموارد المعدنية ، التي تأتي في طليعة الار اضي التي يجب الحفاظ عليها ، واتباع منطق العقلاتية في اختيار مناطق التوسع ، مع مراعاة الجانب الاجتماعي في نوعية النمط الأي قد يرغب المجتمع في السكن فيه واحتسابه المساحات اللازمة وفق معايير معتمدة هو الهـف المباشر والرئيسى للتوسع الحضري ويشكل تحديا لمخططي المدن وصانعي القرار من اجل الايفاء بالمتطلبات الانسانية وضمن روئة تتسم بالشمولية وبمنهجية علمية صحيحة تأخذ بنظر الاعتبار العوامل البيئية ، والاقتصادية ، والاجتماعية . 


\section{ب- تقييم الملاعمة المكانية للأرض الحضرية :}

ان تقييم الملاعمة المكانية هي في جوهر ها عملية تقدير الامكانات المتو افرة في الارض لمختلف

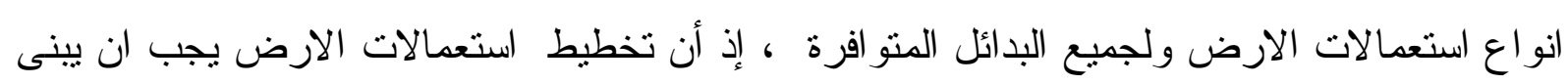
على قاعدة العقلانية من خلال تقييم المو ارد المتاحة . ["] ويمكن تعريفه بانه وسيلة لتخطيط استر اتيجية استعمال الارض إذ يتم من خلاله التتبؤ بالأداء الذي تقدِّمه الارض من خلال الامكانات و القيود

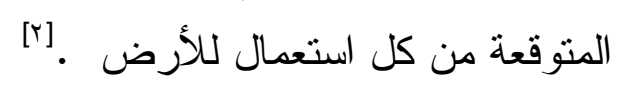

إن الهدف من عملية التقييم هو تحديد الاستعمال الافضل للأرض من الناحية الفعلية و الكامنة ، مع

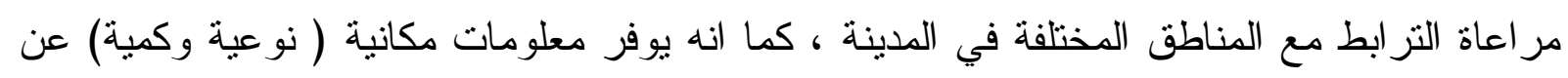

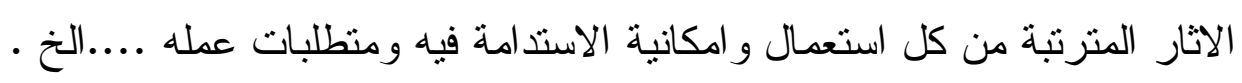

لذلك فان التقييم المستدام للأرض وتخطبط استعمالات الارض يمكن ان يبنى على اساس مستدام عن طريق التكامل بين الملاعمة العمرانية مع الملاعمة الاقتصادية و تقييم الاثار البيئية للاستعمالات السكنية ، و التجارية ، و الصناعية ، و الادارية .... الخ ) لدعم العمل التخطيطي لاستعمالات الارض[ب] كما في المخطط رقم (1) :

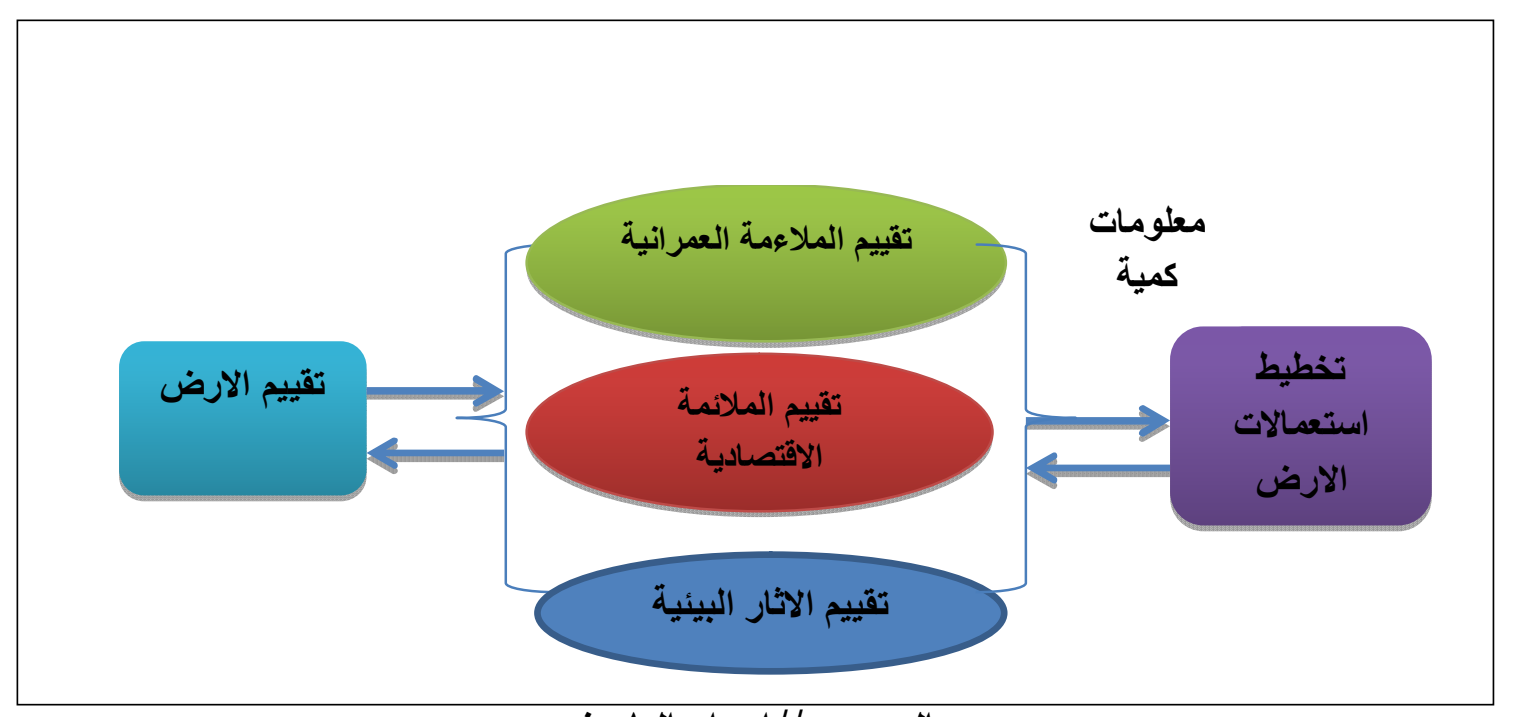

\section{المصدر //اعداد الباحث}

ع - كيفية تقييم الملائمة المكانية للتوسع الحضري لمدينة الكوت :

(1) FAO , " A framework for land evaluation " Published by arrangement with the FAO of the united nations. 1976, p. 1 .

(2) Rossiter , D. G. ,"A theoretical framework for land evaluation." geoderma 72 , . (1996) , p.2

(3)YUAN LI , "Planning support for urban spatial development - A Case Study of Zhenning County"Thesis submitted to the International Institute for Geo-information Science and Earth Observation, NETHERLANDS , 2003 ,p. 17 
يجب وضع الخطة او الطريقة التي سوف يتم على اساسها تقييم الملاعمة المكانية للتوسع الحضري

للمدينة ، و على هذا الاساس فان خطة التقييم سوف تتم على اساس مجموعة من الخطو ات كما يأني :

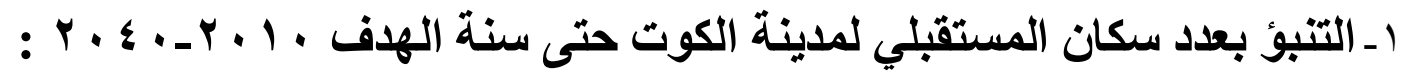

لقد تم التتبؤ بعدد السكان في المدينة لسنة الهدف بالاعتماد على استخر اج معدل النمو من خلال

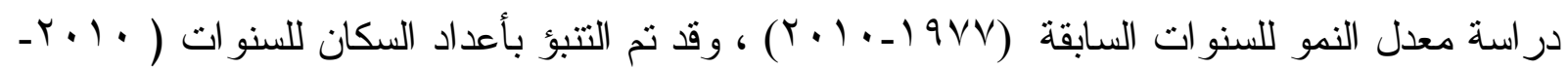
10 وبما إن التوجهات العامة في البلد نحو تقليل حجم الأسرة لعدة أسباب منها ارتفاع المستوى التقافي للمجتمع وكذلك زيادة نسبة النساء المتعلمات في المجتمع و أيضا ارتفاع تكاليف المعيشة و انخفاض مستوى الدخل بشكل عام، وعليه سيحتسب معدل النمو بتناقص بمعدل (0. ., . ) كل خمس سنو ات .حسب تقدير ات الامم المتحدة البالغة (1 . , •) كل • • سنوات و الجدول (1) يبين التتبؤ المستقبلي بعدد.

السكان لمدينة الكوت لسنة الهدف · • • م م

جدول (1)

التنبؤ المستقبلي بعدد السكان لمدينة الكوت لسنة الهدف • ع • ب م

\begin{tabular}{|c|c|c|}
\hline عدد السكان ( نسمة ) & معدل النمو (\%) & السنو ات \\
\hline 317318 & $\Gamma, \varepsilon \cdot$ & 2010 \\
\hline 374151 & 3.35 & 2015 \\
\hline 440097 & 3.30 & 2020 \\
\hline 516415 & 3.25 & 2025 \\
\hline 604502 & 3.20 & 2030 \\
\hline 705901 & 3.15 & 2035 \\
\hline 822313 & 3.10 & 2040 \\
\hline
\end{tabular}

$\mathbf{P}_{\mathrm{f}}=\mathbf{P}_{\mathbf{0}}+(\mathbf{1}+\mathbf{r})^{\mathbf{n}}$

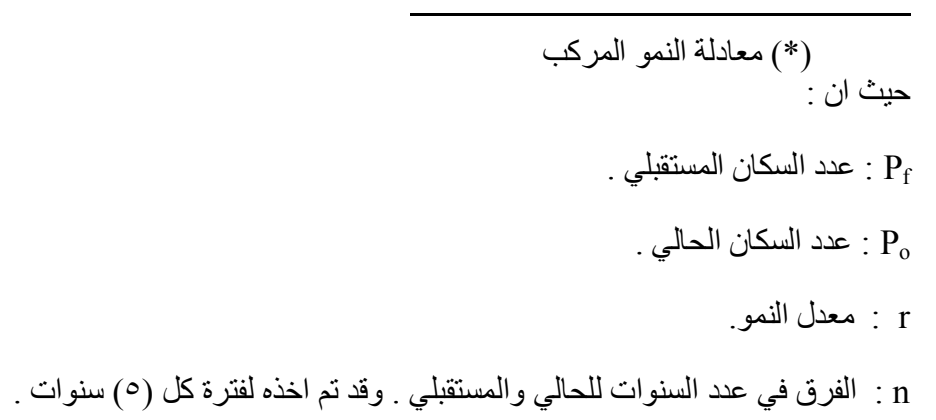


r- حساب المساحة الواجب توفيرها لتلبية العجز السكني في مدينة الكوت حتى سنة

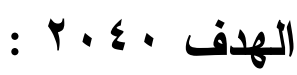

من أجل أن ينم الوقوف على المساحة المطلوبة لاستيعاب الزيادة السكانية المستقبلية لمدينة

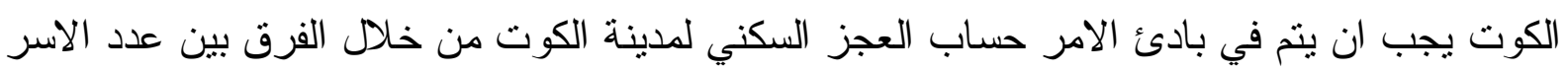

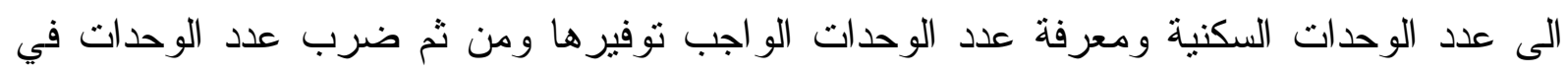

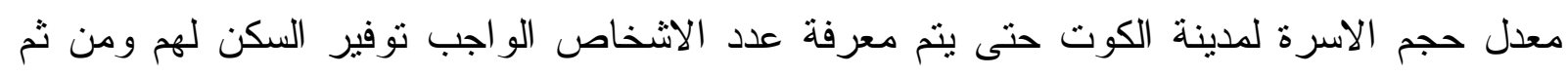

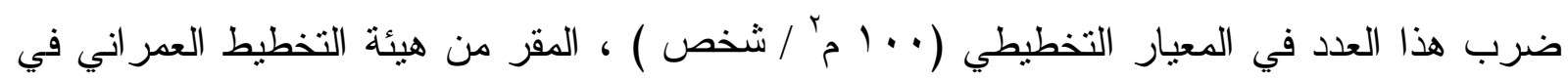

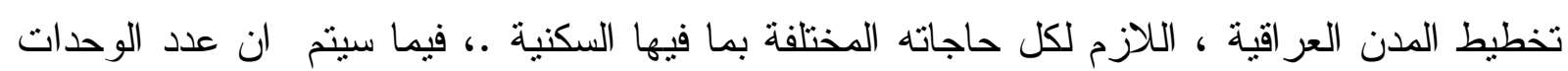

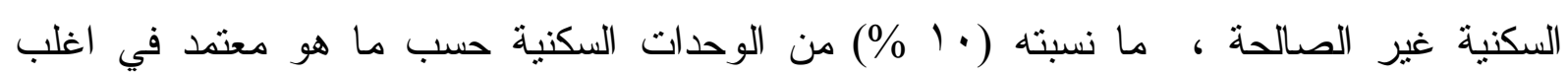
الدر اسات التخطيطية .

العجز السكني الحالي = عدد الاسر الحالي - عدد الوحدات السكنية الصالحة * (•9, •)...( ) . وحدة سكنية $V A V T=(\cdot, 9 \cdot) \leqslant Y r \cdot r-\{0107=$

ولحساب المساحة المطلوبة المطلوب توفرها لسد العجز السكني وبالاعتماد على المعيار التخطيطي

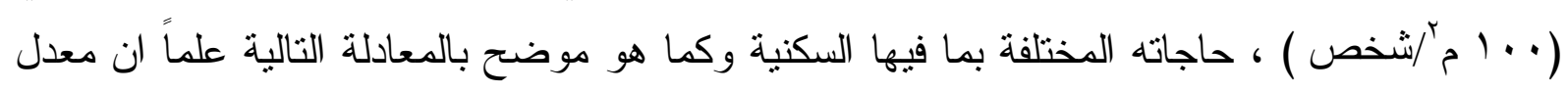

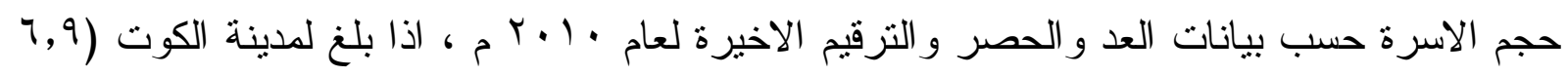

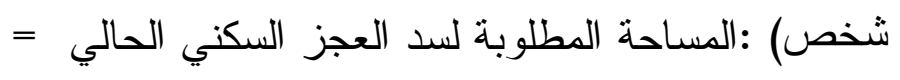

عدد الوحدات المطلوبة ×معدل حجم الاسرة (الحالي) × حصة الثخص الو احد من المساحة

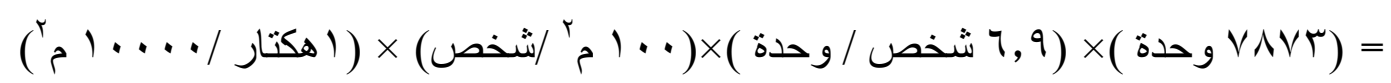
• r = هذا فيما يخص العجز السكني الحالي ، اما فيما يخص الحاجة المستقبلية للأرض فقد تم حسابها

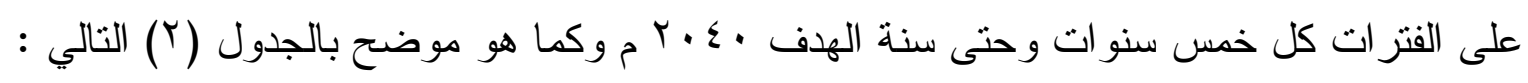


جدول (ז) ( )

المساحة المطلوبة لاستيعاب الزيادة السكانية لمدينة الكوت

\begin{tabular}{|c|c|c|c|}
\hline المساحة الواجب توفيرها حسب المعيار & الزيادة في عدد السكان & عدد السكان & ل لسنوات \\
\hline $0 \leqslant \Gamma, \wedge T$ & & rIVTIA & r.l. \\
\hline $04 \Lambda, r \mu$ & OYAKr & $r V \leqslant 101$ & $r .10$ \\
\hline $709, \leqslant 4$ & $109 \leqslant 9$ & 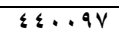 & r.r. \\
\hline VIT,IA & VTrIA & $017 \leqslant 10$ & r.ro \\
\hline$\Lambda \wedge \cdot, \wedge \uparrow$ & $\Lambda \wedge \cdot \wedge \uparrow$ & $T . \leqslant 0 . r$ & $r . r$. \\
\hline $1.14,99$ & 1.11499 & 8.09 .1 & r.ro \\
\hline MIצ, & NIY & AYYTIT & $r \cdot \leq$. \\
\hline $009 \theta, \vee \wedge$ & $0 . \leqslant 9 १ 0$ & & لمجموع \\
\hline
\end{tabular}

اي ان المساحة الكلية المطلوبة = المساحة المطلوبة لسد العجز السكني الحالي + المساحة المطلوبة

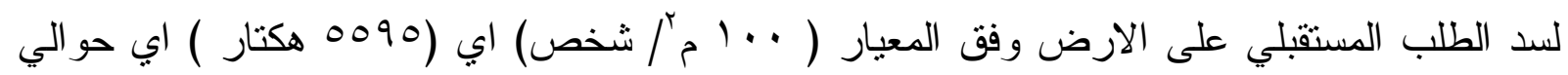
- ( $\left(\begin{array}{lll}r & 07\end{array}\right)$

ז-تحديد الاولويات المهمة في عملية التوسع الحضري : وفي بحثنا سوف تكون الاولوية في التوسع هدفها هو الحفاظ على الار اضي الزر اعية و البساتين ، وكذللك عدم التوسع على حساب الاز اضي التي تحتوي ثروات معدنية (الحقول النفطية ) ، وأن تكون الاولوية على حساب الار اضي غير الصالحة للزر اعة .

عـ تعديد العوامل المؤثرة في التوسع الحضري : وهذه العوامل تتباين من مدينة لأخرى وتتباين كذلك اهميتها النسبية بحسب موقع المدينة وطبيعتها ، وفي بحثنا فانه نم تحديد جملة من العوامل المؤثزة في التوسع الحضري للمدينة وهي : أ- منطقة الار اضي الزر اعية و البساتين • ب- الثروات المعدنية ( الحقول النفطية في منطقة الدر اسة ) . ت- شبكة الطرق في المدينة وسهولة الوصول . ث- البعد عن مركز المدينة . ج- الربط مع المنطقة الحضرية الحالية . ح- نوعية التربة .

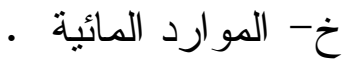


د-نأثير القاعدة الجوية ( المطار ).

ومن الجدير بالذكر أن هنالك عو امل اخرى تؤثر في التوسع الحضري للمدن كالطبوغر افية ونأثيرات

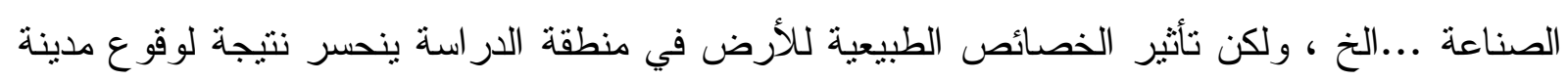

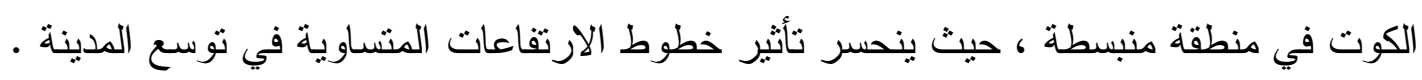
اما من ناحية تأثير ات الصناعة فان هذا التأثثر يكاد يكون معدوماً لعدم وجود الصناعات ذات التأثير

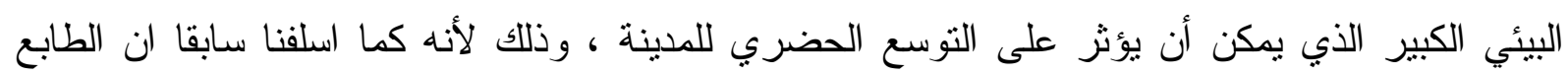

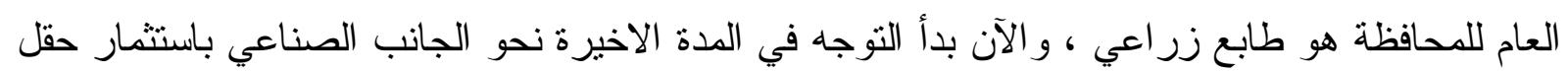

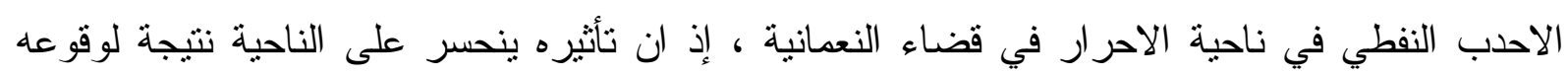

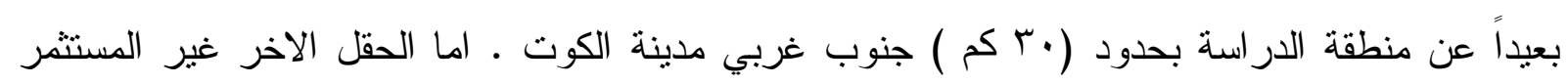

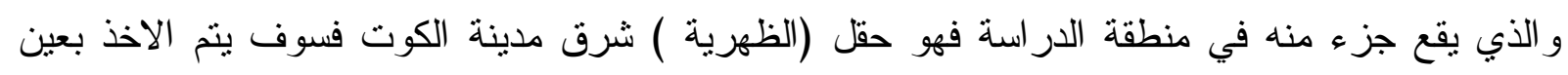
الاهتمام تأثير ات استثماره في المستقبل ـ و الخارطة (1) تنين العوامل المؤثرة المختارة في توسع الددينة

○ـ تصنيف البيانات المكانية : إذ يتم التقسيم الى عشرة انطقة متساوية البعد عن العامل المؤثر بواسطة

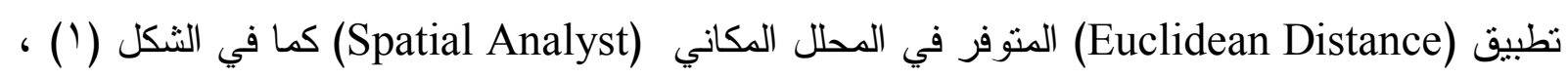

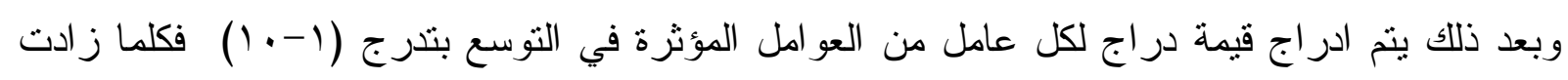

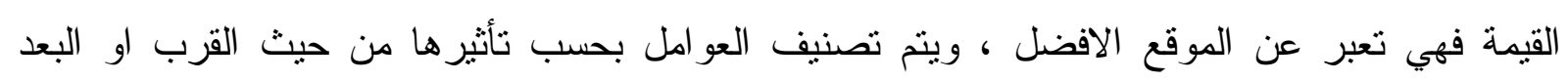

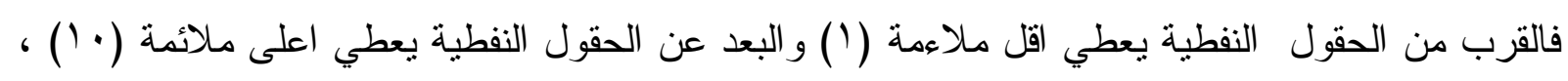

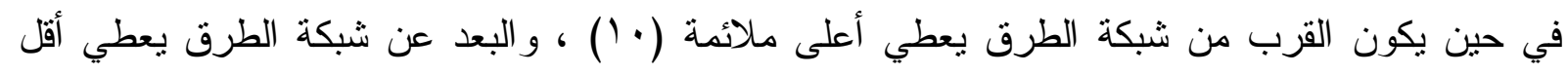

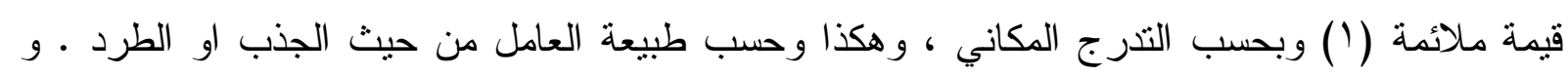

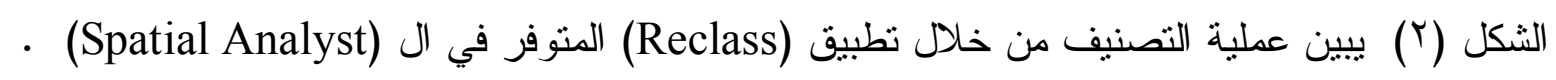


العدد الثاني عشّر

لة كلية التربية / واسط

خارطة (1)

العوامل المؤثرة المختارة في توسع المدينة

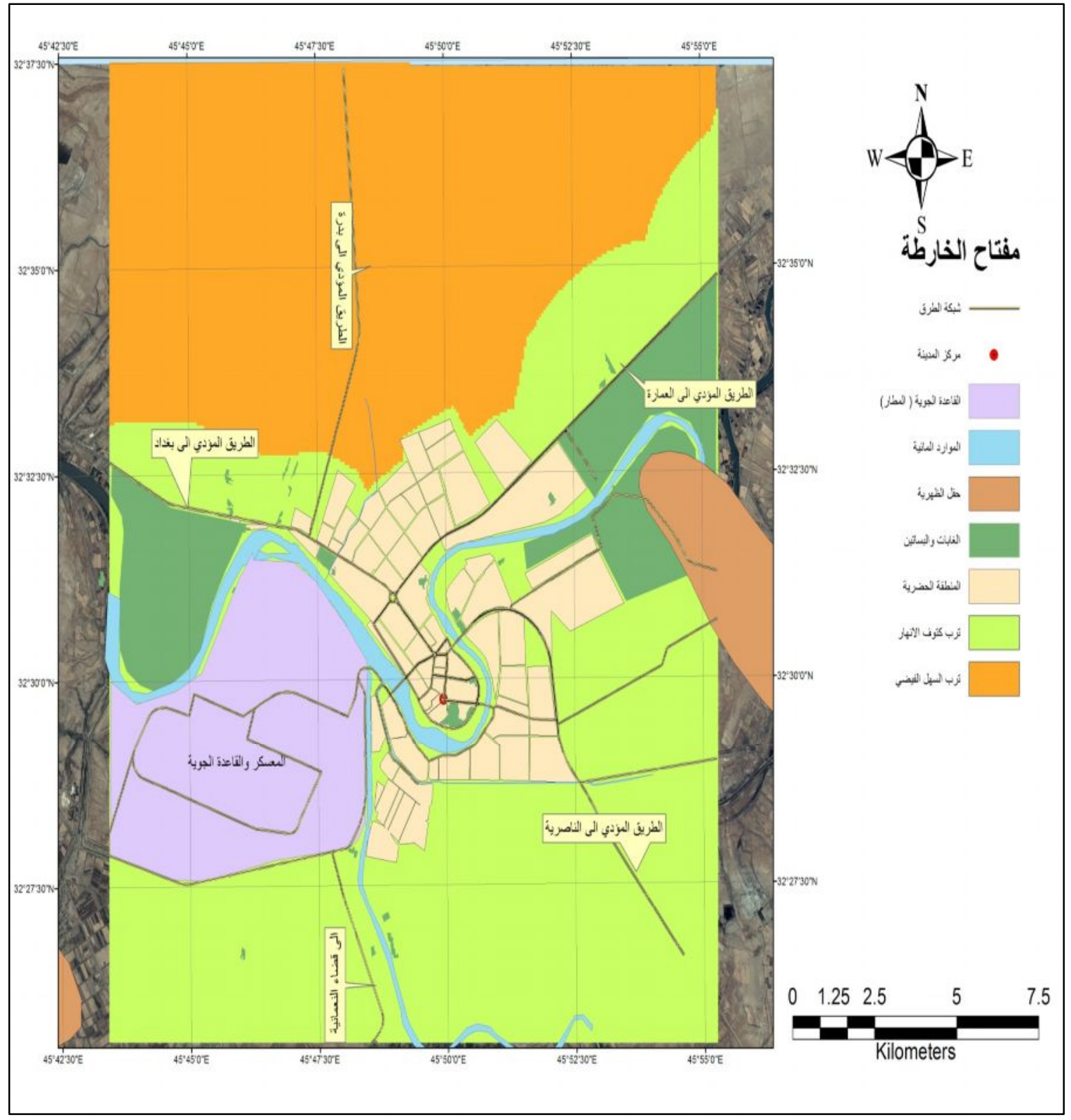




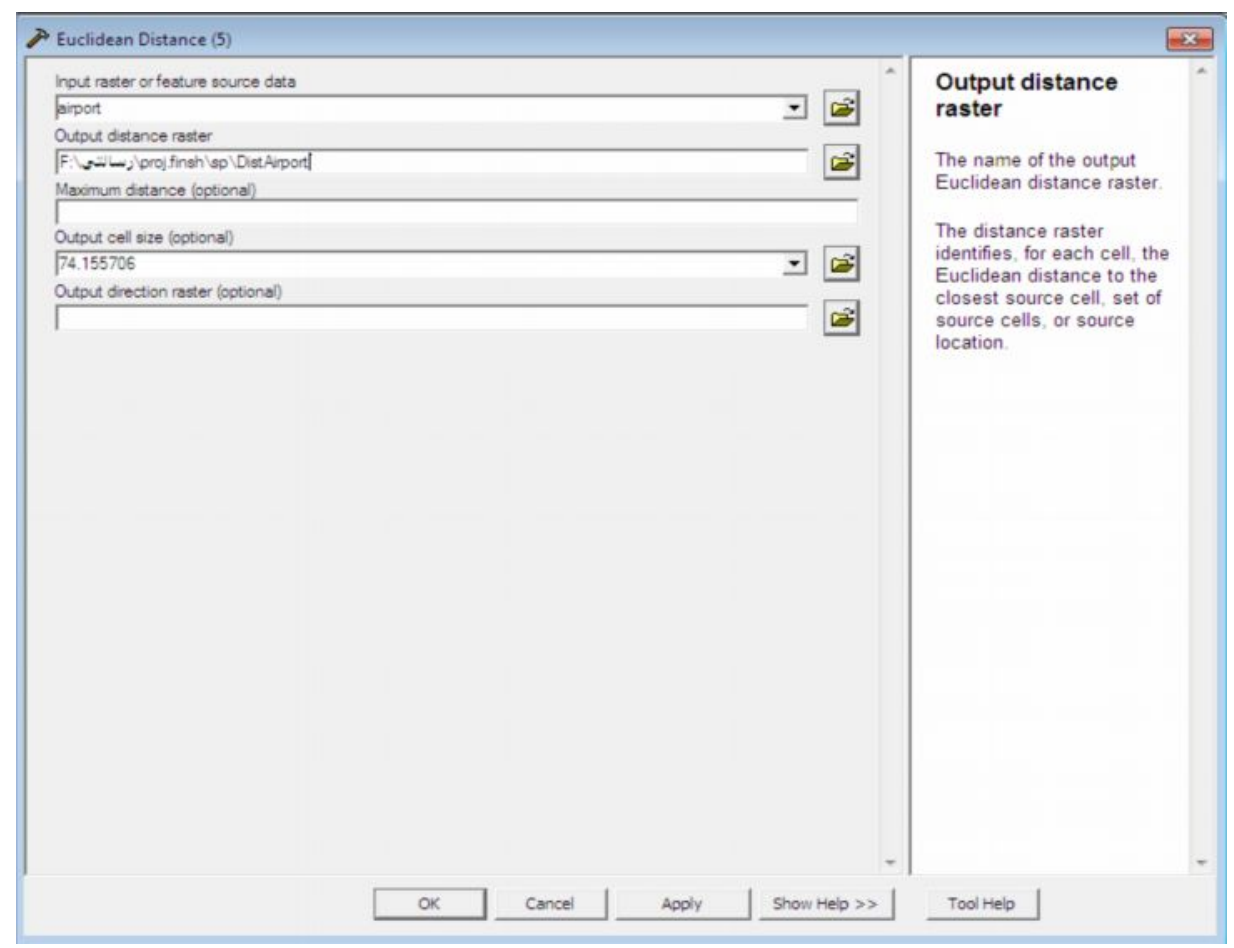

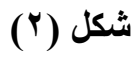

عملية التصنيف من خلال تطبيق (Reclass) المتوفر في ال (Spatial Analyst)

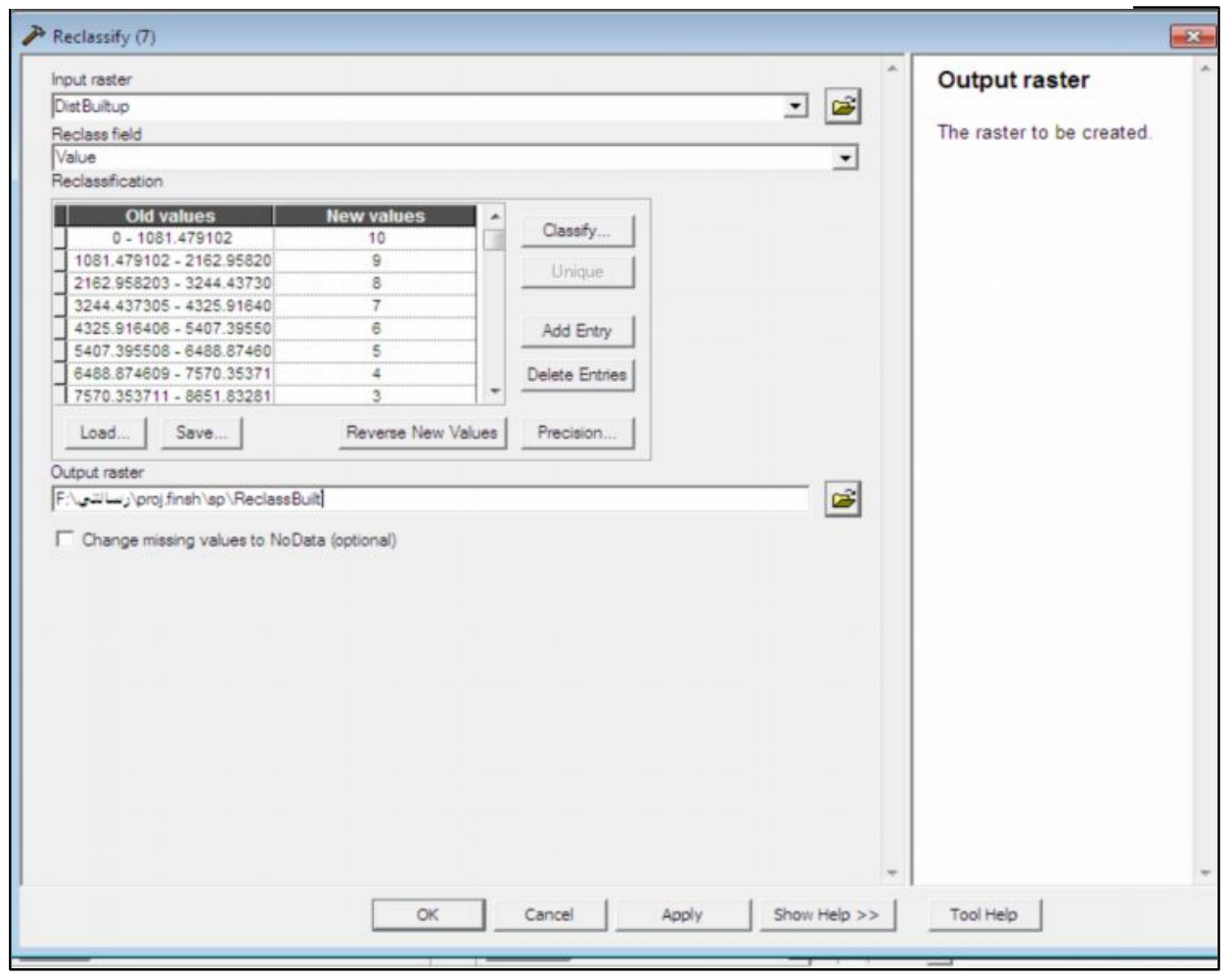


T-اعطاء الاوزان للعوامل (الطبقات) المؤثرة : وذلك حسب درجة تأثثرها في التوسع الحضري

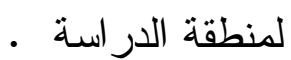
V-عملية دمج العوامل (الطبقات) : حسب درجة التأثثر النسبي (Influence) ، وبيان المو اقع الاكثر

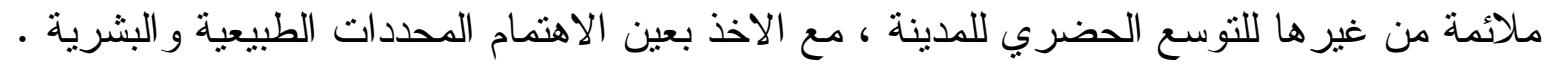

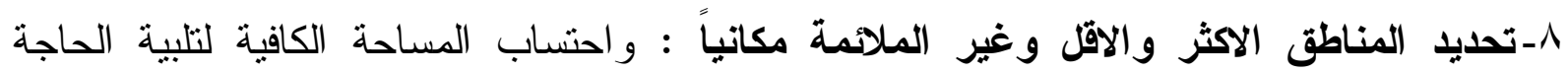

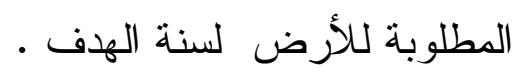
هـالعوامل المؤثرة في التوسع الحضري لمدينة الكوت وتصنيف تأثثرها :

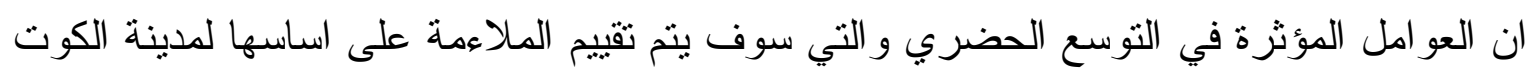
هي كما يأتي : هـ ا ـ الموارد النفطية والثروات المعدنية : بالنسبة لتأثير هذا العامل فقد تم الأخذ بعين الاهتمام و وجود حقل الظهرية النفطي شرقي مدينة

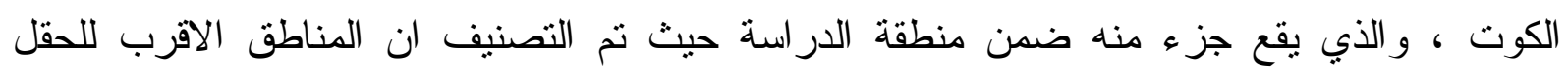

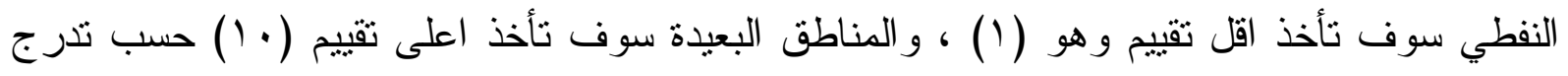

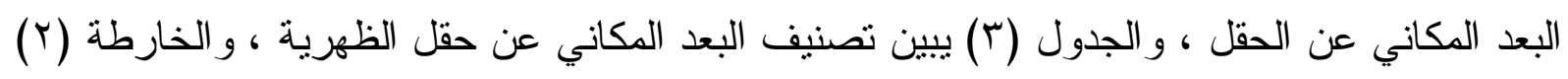
:تبين نتائج التصنيف :

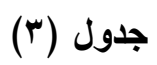

تصنيف درجة البعد المكاني عن الموارد الطبيعية والثزوات المعدنية (حقل الظهرية)

\begin{tabular}{|c|c|c|c|}
\hline درجة التصنيف & البعد عن الحقل النفطي (م) & درجة التصنيف & البعد عن الحقل النفطي (م) \\
\hline 7 & $|r| 7 \Lambda-1.1 \varepsilon$. & 1 & $r \cdot r \wedge-$. \\
\hline v & $1 \leqslant 197-1 Y 171$ & r & $\varepsilon .07-Y . Y \Lambda$ \\
\hline$\wedge$ & $17 K r \leq-1 \leq 197$ & r & $7.1 \leqslant-\leqslant .07$ \\
\hline 9 & MAOT - ITYTE & $\varepsilon$ & $\Lambda \| Y-Y \cdot \Lambda \varepsilon$ \\
\hline 1. & r. YA. -INYOOY & 0 & $1.1 \leq .-111 r$ \\
\hline
\end{tabular}


خارطة (r)

نتيجة تصنيف البعد عن حقل الظهرية النفطي

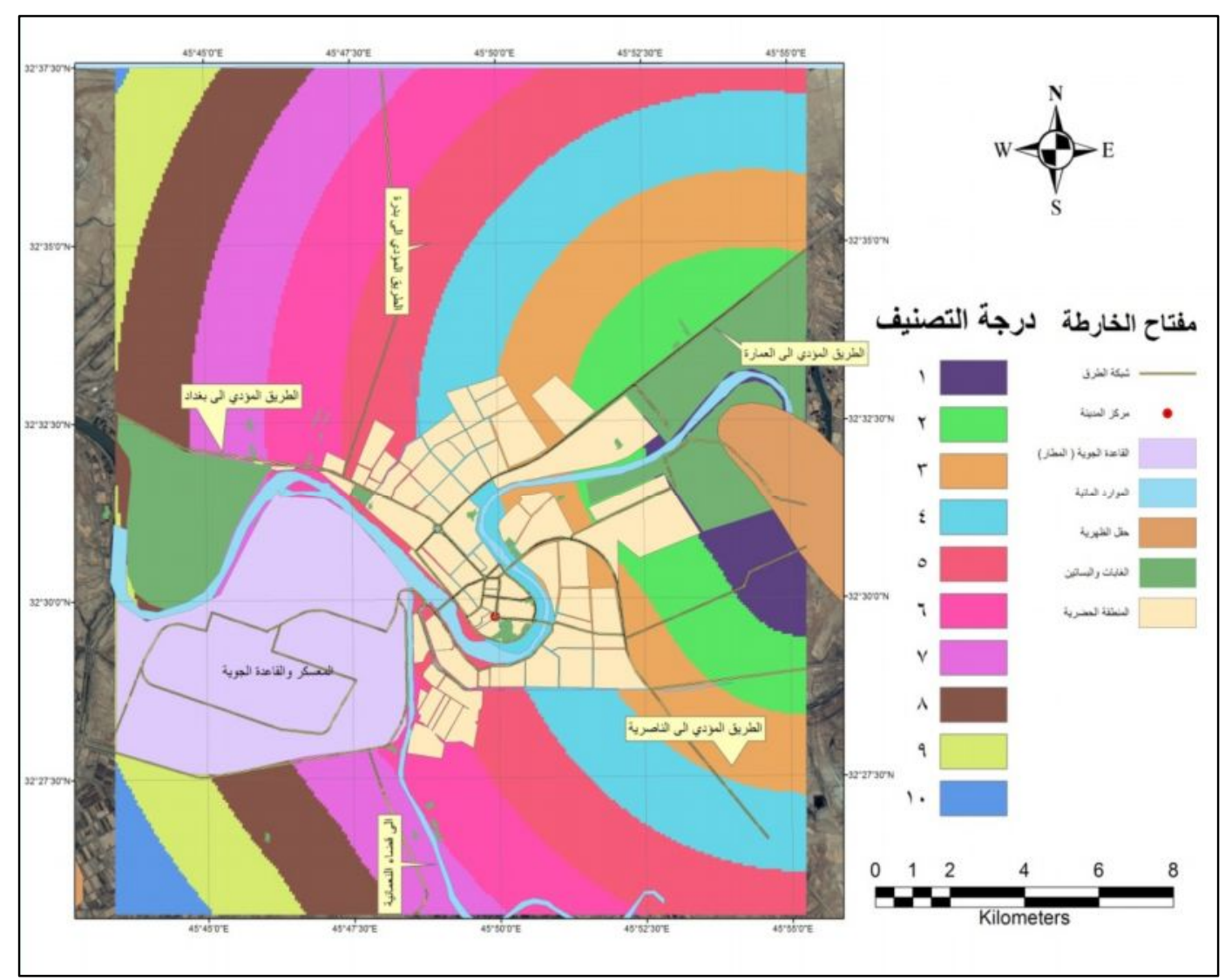

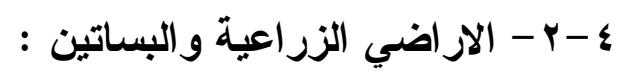

إن الحفاظ على الار اضي الزر اعية و البساتين سوف يأخذ الاولوية في التوسع الحضري من أجل ضمان استدامة الموارد الطبيعية حيث سوف يتم اعطاء اقل قيمة تصنيف (1) للأر اضي القريبة من الار اضي الزر اعية ، و اعطاء اعلى قيمة (· () للأر اضي البعيدة عن الار اضي الزراعية والبساتين ، لضمان عدم التوسع على حسابها وبالتالي قضم مساحات كبيرة من الار اضي الخصبة ، لا سيما أن مدينة الكوت كما اسلفنا قد عانت من التجاوز على هذه الار اضي وتحويل استعمالها من الاستعمال الزر اعي الى الاستعمال السكني في ظل انعدام سلطة القانون بعد عام r ب .r م •وقد تم تحديد وتصنيف درجة البعد المكاني عن الاراضي الزر اعية كما في الجدول (ع) ، و الخارطة (r) تبين نتائج التصنيف : 
جدول (๕)

تصنيف درجة البعد المكاني عن الاراضي الزراعية

\begin{tabular}{|c|c|c|c|}
\hline درجة التصنيف & البعد عن الاراضي الزراعية (م) & درجة التصنيف & البعد عن الاراضي الزراعية (م) \\
\hline 7 & $09 \leqslant \cdot-\leqslant 90$. & 1 & $99 \cdot-\cdot$ \\
\hline $\mathrm{V}$ & $791 .-095$. & r & $191 .-99$. \\
\hline$\Lambda$ & V9r. - 79r. & $r$ & YqV. - 191. \\
\hline 9 & (19). - Vqr. & $\varepsilon$ & rq7. -rqV. \\
\hline 1. & $99 \ldots-191$. & 0 & $590 .-197$. \\
\hline
\end{tabular}


צ - - -تاثير وجود القاعدة الجوية (المطار العكري) :

هناك توجه لدى المحافظة نحو تحويل المطار العسكري الى مطار مدني، وعليه فهو يعد عنبة

بشرية لتوسع المدينة بهذا الاتجاه ومن ثم فان الاماكن الأقرب الى القاعدة العسكرية ( المطار) سوف تأخذ اقل تقييم (1) و المناطق الابعد سوف تأخذ اعلى نقييم (•) (1) بحسب تدرج البعد المكاني عن القاعدة الجوية ـ و الجدول (0) ييين تصنيف البعد المكاني للبعد عن القاعدة الجوية ، والخارطة (ع) تبين نتيجة التصنيف : n ؟ - ـ - القرب من شبكة الطرق :

تلعب شبكة الطرق وسهولة الوصول دوراً ايجابيا نحو جذب المستقر ات البشرية ، إذ لا يمكن

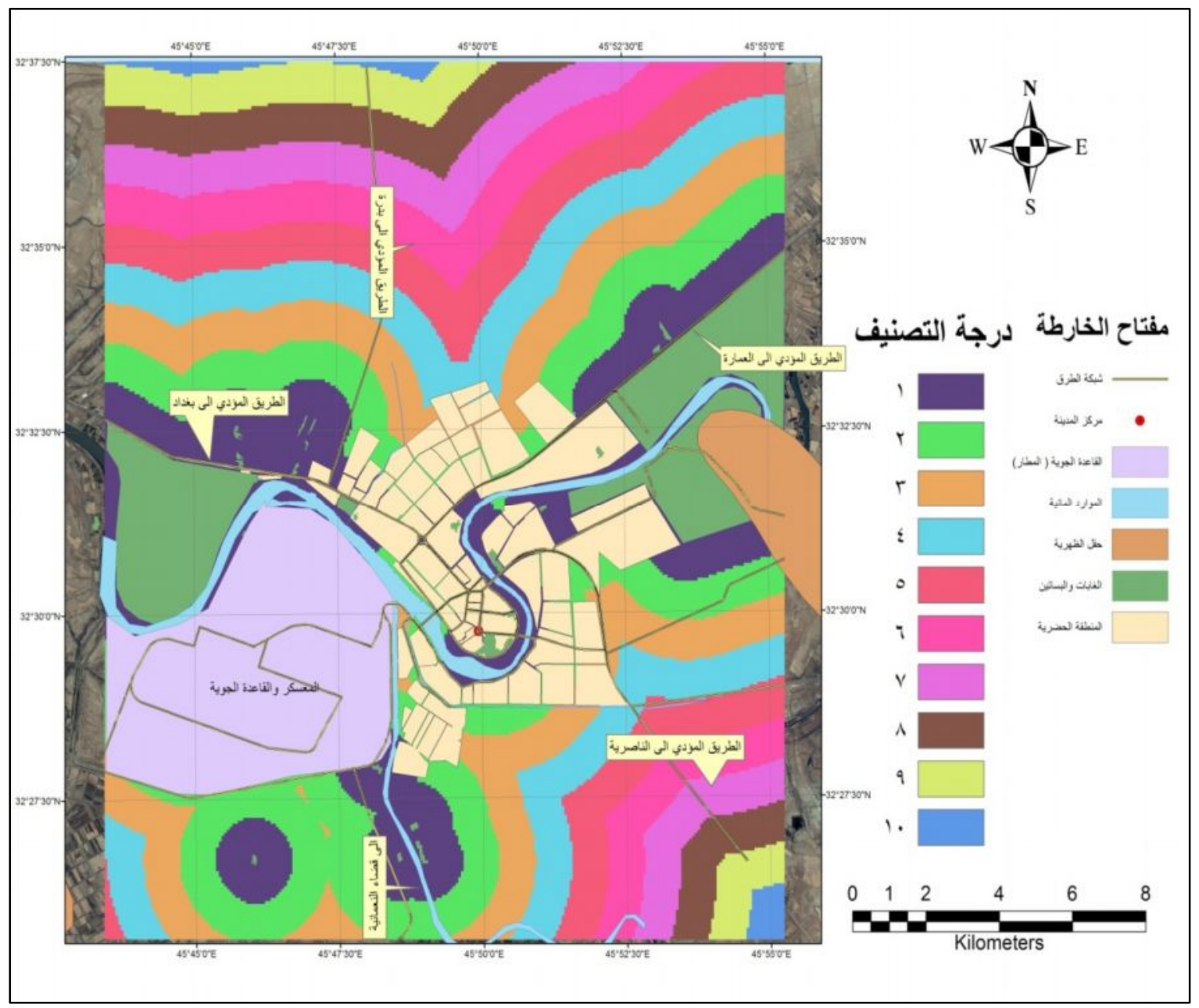

للمدينة ان تتفاعل مع بعضها البعض من دون شبكة الطرق ويصبح من الصعب تأدية وظائف 
الاستعمالات الاخرى للأرض داخل المدن • ان العلاقة بين شبكات الطرق وبين التجمعات الحضرية وثثقة وحساسة ، إذ ان التلاحم بين السكان و الطرق على اعلى درجاته داخل التجمع نفسه ، و وعلى هذا الاساس فقد تم الأخذ بان المناطق الاقرب لشبكة الطرق فأنها سوف تأخذ أعلى تقييم ( • () و اما المناطق البعيدة عن شبكة الطرق فأنها سوف تأخذ اقل تقييم (1) بحسب تدرج البعد المكاني عن شبكة الطرق • و الجدول (7) يبين تصنيف درجة البعد المكاني عن شبكة الطرق ، و الخارطة (0) تبين نتيجة التصنيف

(') جدول

تصنيف درجة البعد المكاني عن شبكة الطرق

\begin{tabular}{|c|c|c|c|}
\hline درجة التصنيف & القرب من شبكة الطرق (م) & درجة التصنيف & القرب من شبكة الطرق (م) \\
\hline 0 & $\varepsilon r \cdot r-r O \wedge O$ & 1. & $V \backslash V_{-} \cdot$ \\
\hline$\varepsilon$ & $0.19-\Sigma T . Y$ & 9 & $1 \leqslant \Gamma \xi-V \mid V$ \\
\hline $\bar{r}$ & $0 V M 7-0.19$ & $\Lambda$ & $r 101-1 \leqslant r \varepsilon$ \\
\hline T & TEOT_OVMT & $\mathrm{V}$ & TATA - Y101 \\
\hline 1 & $V I V \cdot-T \leqslant O r$ & 7 & rOAO - YATA \\
\hline
\end{tabular}

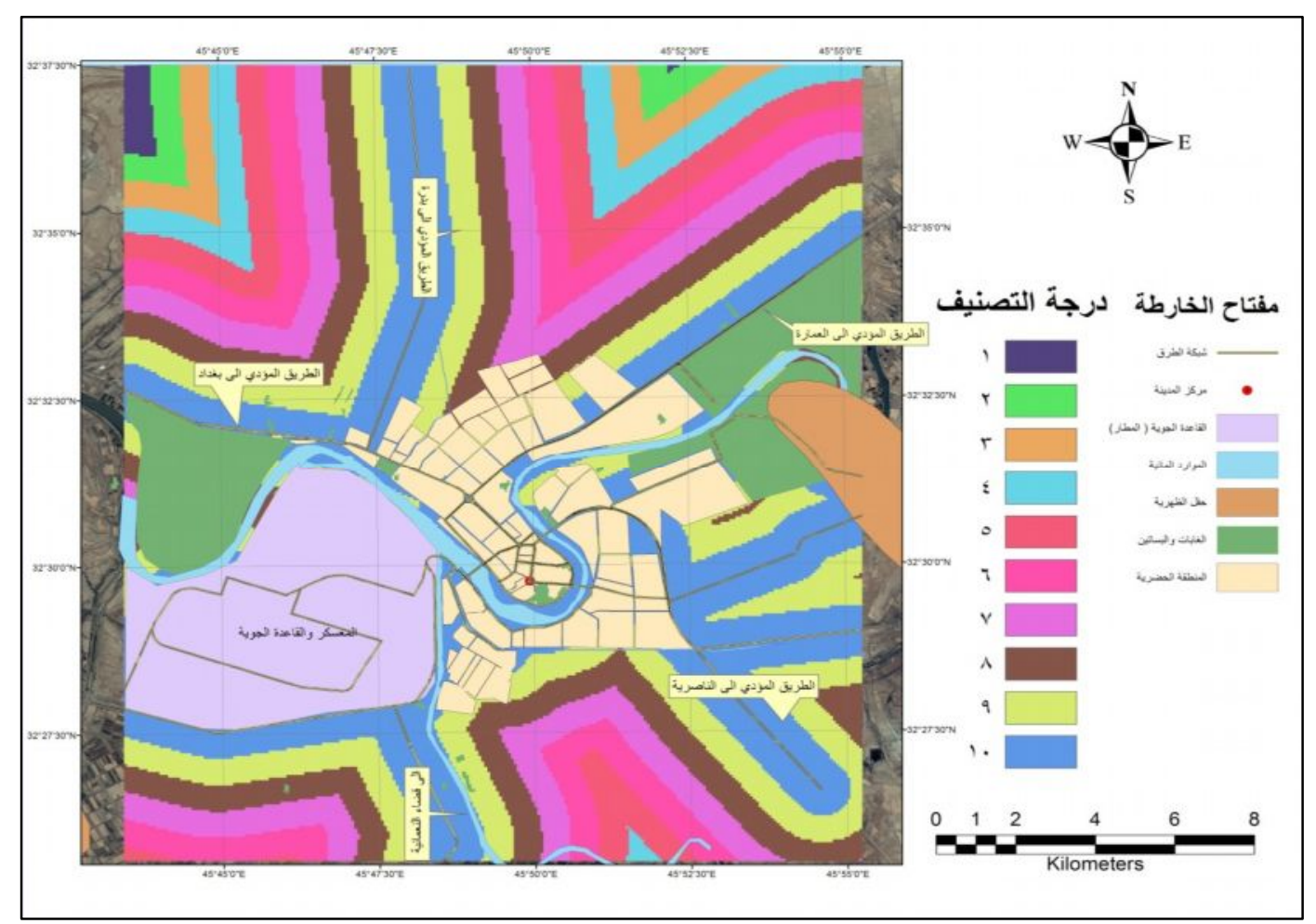




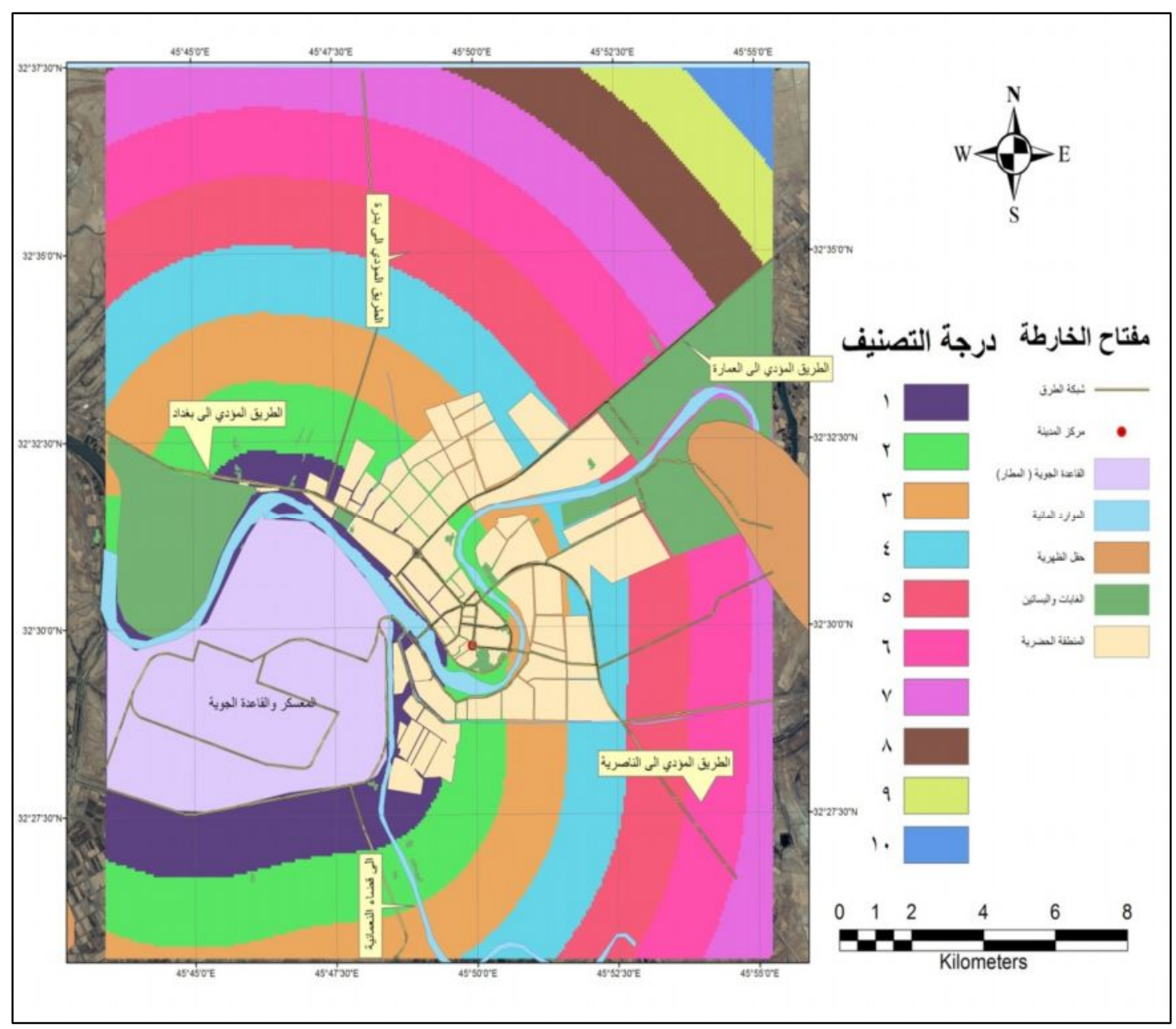

- - - - - القرب من المنطقة الحضرية :

يساهم القرب من المنطقة الحضرية في الربط مع المدينة مع حدودها الحالية ، وهو بالتالي سوف يساهم في تقليل الكلفة الاقتصادية لمد خدمات البنى التحتية ، وتوسع شبكة الطرق فضلا على الى انه يساهم في عملية التجانس الحضري بين المناطق السكنية الحالية ومناطق التوسع المستقبلي ،

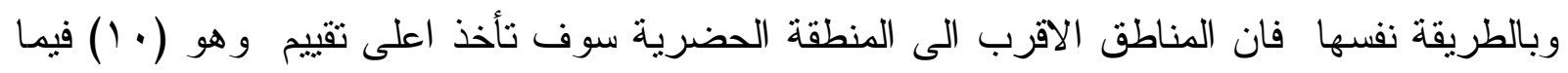
سوف تحصل المناطق البعيدة على اقل تقييم وهو (1) وحسب تدرج البعد المكاني عن المنطقة الحضرية . و الجدول (V) يبين البعد المكاني عن المنطقة الحضرية ودرجة تصنيفه ،و الخارطة (T) تنين نتائج التصنيف : n 
جدول (v)

تصنيف درجة البعد المكاني بالنسبة للقرب من المنطقة الحضرية

\begin{tabular}{|c|c|c|c|}
\hline درجة التصنيف & القرب من المنطقة الحضريـة (م) & درجة التصنيف & القرب من المنطقة الحضرية (م) \\
\hline 0 & $T \leq \wedge T-0 \leq .0$ & 1. & $1.11-$. \\
\hline$\varepsilon$ & VOTV $-7 \leqslant \Lambda T$ & 9 & rITr-1.11 \\
\hline$r$ & ᄉT $\leqslant \Lambda-V 07 V$ & $\wedge$ & $\left.r r \leqslant r-r_{6}\right) T r$ \\
\hline r & $q \vee Y q-\Lambda T \leq \Lambda$ & V & $\varepsilon r T \leq-\mu r \leqslant r$ \\
\hline 1 & $1 \cdot 11 \cdot-q \vee r q$ & 7 & $0 \leqslant .0-\leqslant M Y \leqslant$ \\
\hline
\end{tabular}

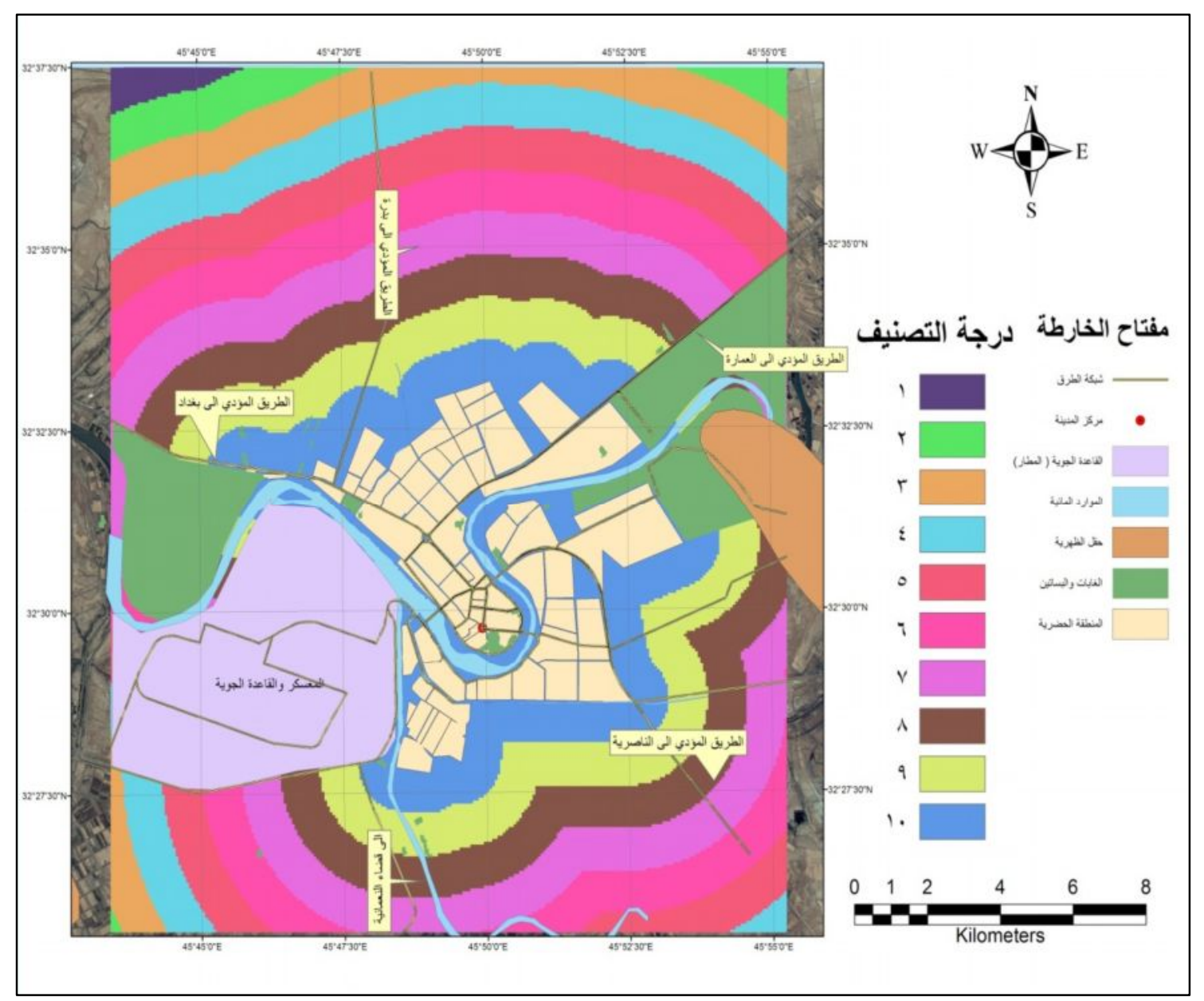




\section{ץ- - - - - القرب من مركز المدينة وسهولة الوصول :}

إن مسألة البعد عن مركز المدينة يعطي مؤشراً لسهولة الوصول للفعاليات الموجودة في مركز الددينة فكلما كانت المنطقة اقرب الى مركز المدينة كانت سهولة الوصول اليها افضل على الرغم من سن أن مسألة القرب و البعد قد اصبحت نسبية في حالة توفر شبكات طرق ووسائل نقل حديثة وسريعة ،لان هنالك عو امل اصبحت مسالة سهولة الوصول نتأثر بها بصورة اكبر ، وهي الوقت ، و الزمن

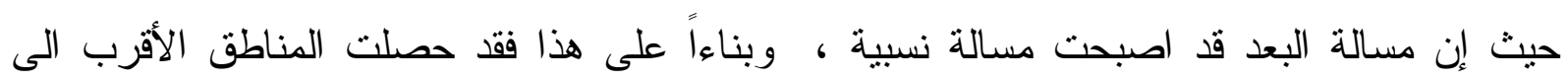
مركز المدينة على اعلى درجة تقييم (• () ، فيما حصلت المناطق البعيدة على مركز المدينة على اقل درجة تقييم (1) وبحسب تدرج البعد الدكاني عن مركز الددينة .والجدول (^) يبين تصنيف البعد مردي

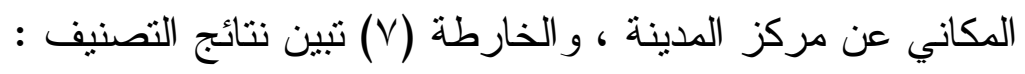

\section{جدول (^)}

تصنيف درجة البعد المكاني بالنسبة للقرب من مركز المدينة

\begin{tabular}{|c|c|c|c|}
\hline درجة التصنيف & القرب من مركز المدينة (م) & درجة التصنيف & القرب من مركز المدينة (م) \\
\hline 0 & $1.50 \Lambda-\Lambda V 10$ & 1. & $\mid v \leq r-$. \\
\hline$\varepsilon$ & $1 K r \cdot 1-1 \cdot \leq 01$ & 9 & $r \leqslant \wedge r-I V \leqslant r$ \\
\hline r & $1 r q \leq \varepsilon-1 K r \cdot 1$ & $\wedge$ & OrYq - r $\leqslant \wedge T$ \\
\hline r & $1071 V-1149 \varepsilon \varepsilon$ & 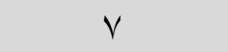 & T9Yr - OrYq \\
\hline 1 & $1 \mathrm{~V} \leqslant \mathrm{r} .-104 \mathrm{NV}$ & 7 & $\Lambda V 10-79 V Y$ \\
\hline
\end{tabular}

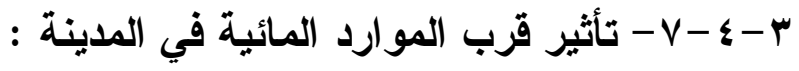

يسهم وجود المو ارد المائية نحو جذب المستقر ات البشرية و التشجيع على تجمع السكان لأهميتها في حياة الانسان ، فضلاً عن ان اغلب الفعاليات والانشطة تكون بالقرب من الموارد المائية ، ويقع المورد المائي ( نهر دجلة في وسط المدينة ويقسمها الى قسمين كما اسلفنا سابقاً ) ، وعلى هذا الاساس فقد تم اعطاء اعلى تقييم للمناطق القريبة من الموارد المائية ( • () ، و أما المناطق البعيدة عن الموارد المائية فقد حصلت على اقل تصنيف وهو (1) حسب تدرج البعد المكاني عن الموارد المائية . 
و الجدول (9) يبين تصنيف البعد المكاني عن الموارد المائية ، و الخارطة (^) تنين نتائج تصنيف تأثير المو ارد المائية :

\section{جدول (9)}

تصنيف درجة البعد المكاني بالنسبة للموارد المائية

\begin{tabular}{|c|c|c|c|}
\hline درجة التصنيف & القرب من الموارد المائية (م) & درجة التصنيف & القرب من الموارد المائية (م) \\
\hline 0 & $\neg \leqslant \Lambda .-0 \leqslant \ldots$ & 1. & $1.1 .-$. \\
\hline$\varepsilon$ & V०T. $-7 \leqslant \Lambda$. & 9 & $1,080-2160$ \\
\hline$r$ & ヘTร. -V0T. & $\wedge$ & TrE. - r6lT. \\
\hline r & qVT. - ATE. & v & ETr. - r T \\
\hline 1 & $1.1 \ldots-9 \vee r$. & 7 & $0 \varepsilon \ldots-\varepsilon r r$. \\
\hline
\end{tabular}

خارطة (v)

تصنيف درجة البعد المكاني عن مركز المدينة

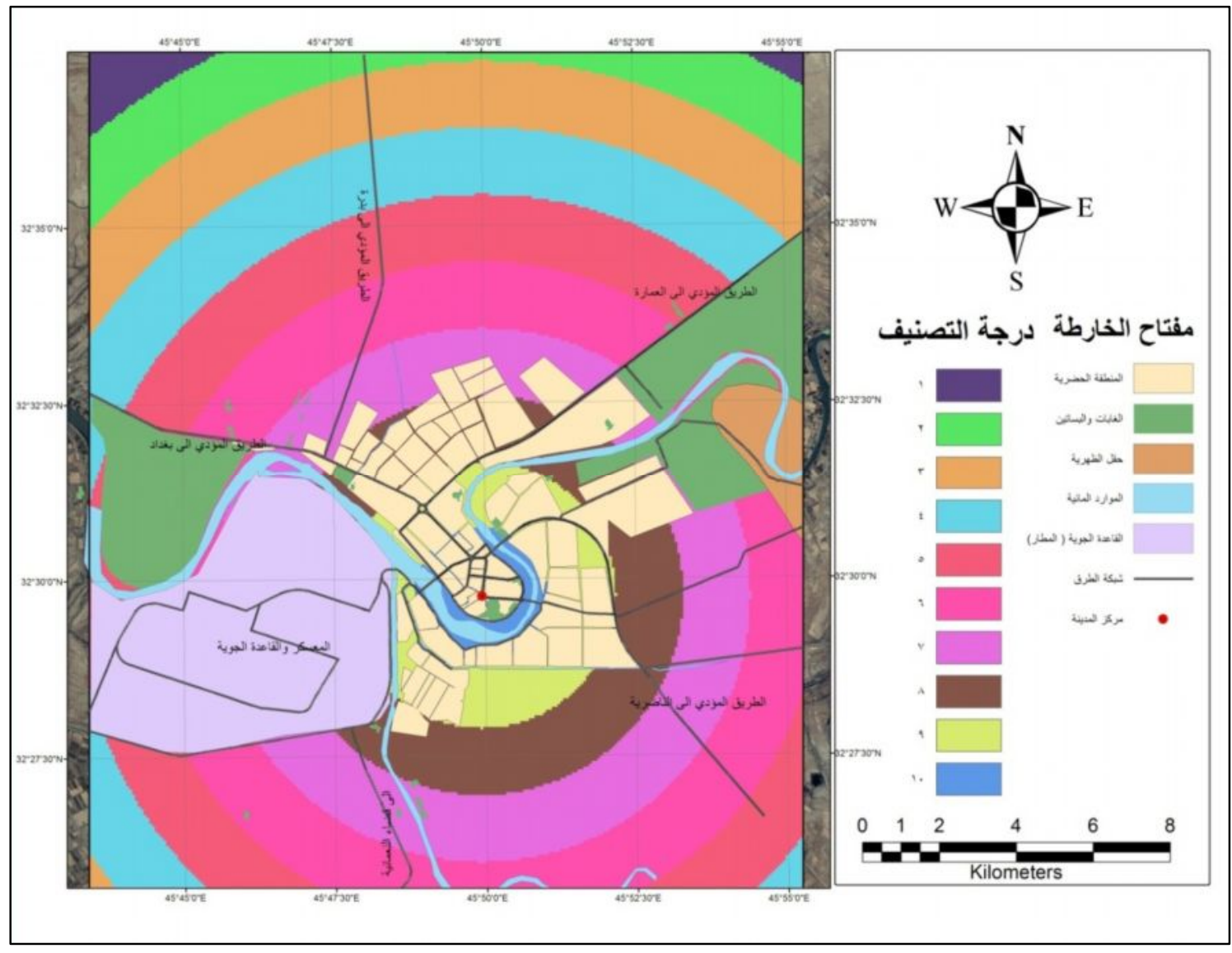


خارطة (^)

تصنيف درجة البعد المكاني عن الموارد المائية

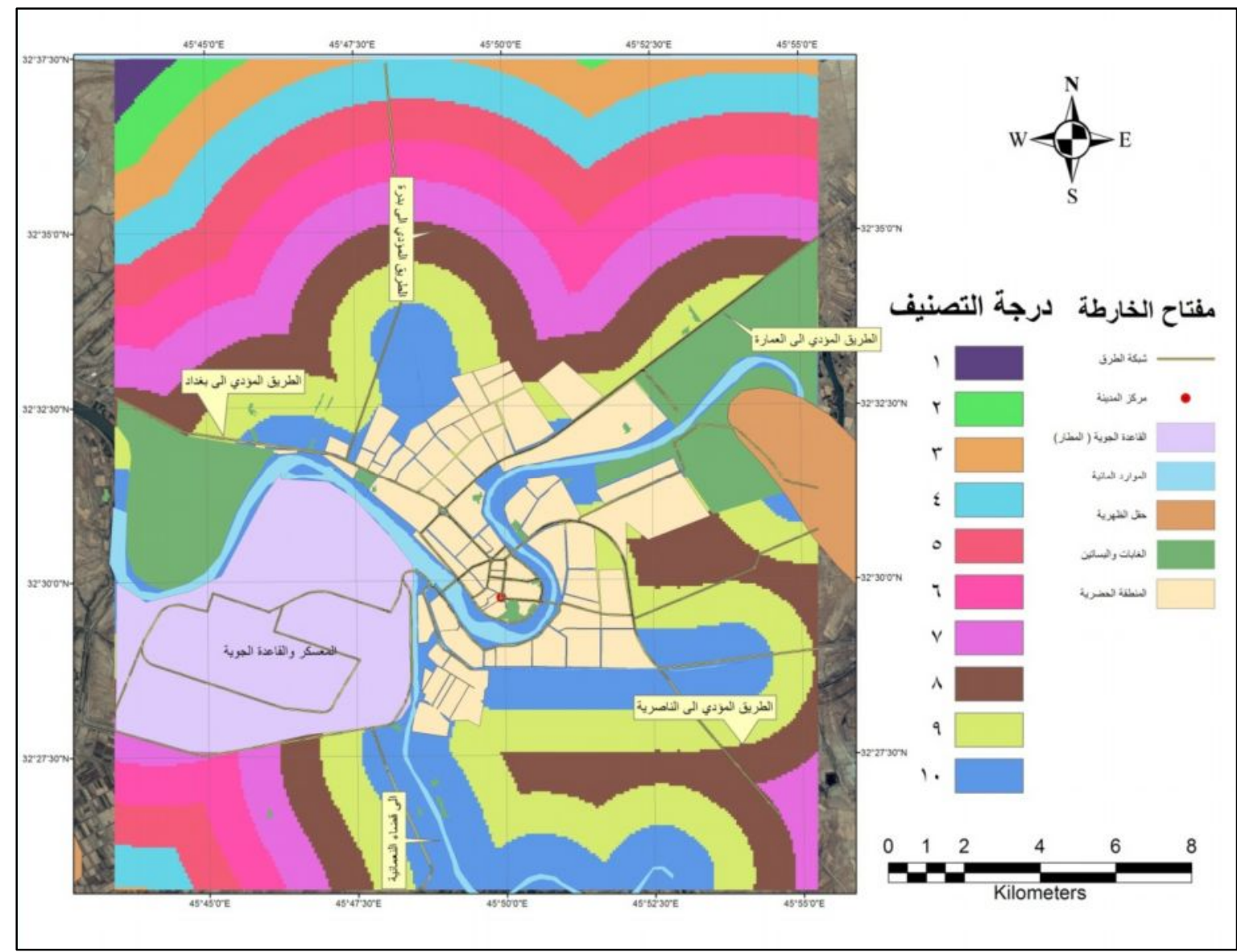

: ب-

تُقسَّم انواع الترب في منطقة الدراسة على صنفين : صنف ترب السهل الفيضي والتي سوف

تحصل على اعلى درجة تقييم (· () ، وصنف ترب كتوف الانهار و التي تقع على ضفاف الانهار ،

وسوف تحصل على تقييم (0) ، و الخارطة (9) تنين نتائج تصنيف انو اع الترب لمدينة الكوت . 


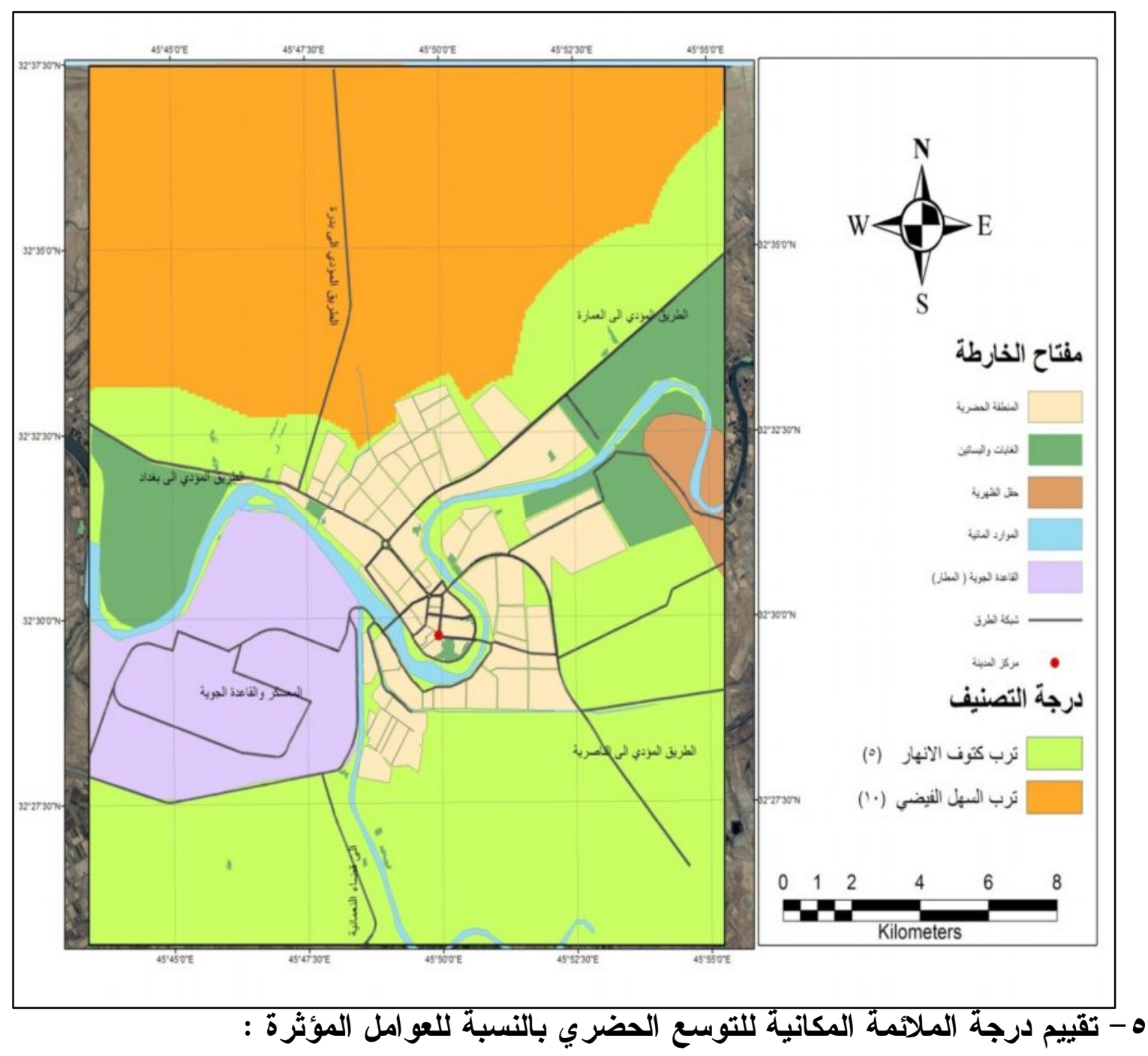

بعد بيان تأثير كل من العو امل المؤثرة في التوسع الحضري للمدينة ، سوف يتم في هذه المرحلة تقييم الملاعمة المكانية على وفقا لدرجة الاهمية النسبية ، وحسب المبررات المعطاة لكل عامل من حيث اهميته المذكورة اثثاء عملية التصنيف ، وسوف يتم ذلك عبر اعطاء الاوزان لهذه العوامل و اجر اء عملية التطابق الموزون ( Weighted Overlay) المتوفر في بيئة نظم المعلومات الجغر افية ضمن تطبيقات المحلل المكاني (Spatial Analyst) ، إذ تم اعطاء الاوزان حسب الاهمية النسبية للعو امل كما مبين بالجدول ( · ) : 
جدول(·)

درجة الاهمية للعوامل المؤثرة في التوسع الحضري لمدينة الكوت

\begin{tabular}{|c|c|c|}
\hline درجة الاهمية & العامل المؤثر في التوسع الحضري & $ت$ \\
\hline$\% 1 \leq$ & الموارد النفطية والثروات المعدنية & 1 \\
\hline$\%$ & الحفاظ على الاراضي الزراعية والبساتين & r \\
\hline$\%$ ir & تأثير وجود القاعدة الجوية (المطار العكري) & $\mu$ \\
\hline$\%$ ir & القرب من شبكة الطرق وعامل سهولة الوصول & $\varepsilon$ \\
\hline$\%$ iv & القرب من المنطقة الحضرية & o \\
\hline$\% 1$ & القرب من مركز المدينة & 7 \\
\hline$\% 11$ & تأثير الموارد المائية في المدينة & V \\
\hline$\% 11$ & تأثير نوع التربة & $\wedge$ \\
\hline$\% 1 \ldots$ & 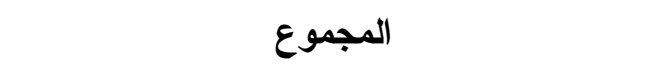 & \\
\hline
\end{tabular}

و بعد اجر اء عملية التطابق الموزون سوف نظهر نتائج تعكس وجود ثناثة انماط من انواع الارض ، و هي المناطق الاكثر و الاقل وغير الملائمة مكانياً للتوسع الحضري ، و الثنكل (r) بيين كيفية عمل اجر اء التطابق الموزون في تطبيقات المحلل المكاني (Spatial Analyst) : 


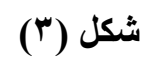

عملية التطابق الموزون (Weighted Overlay)

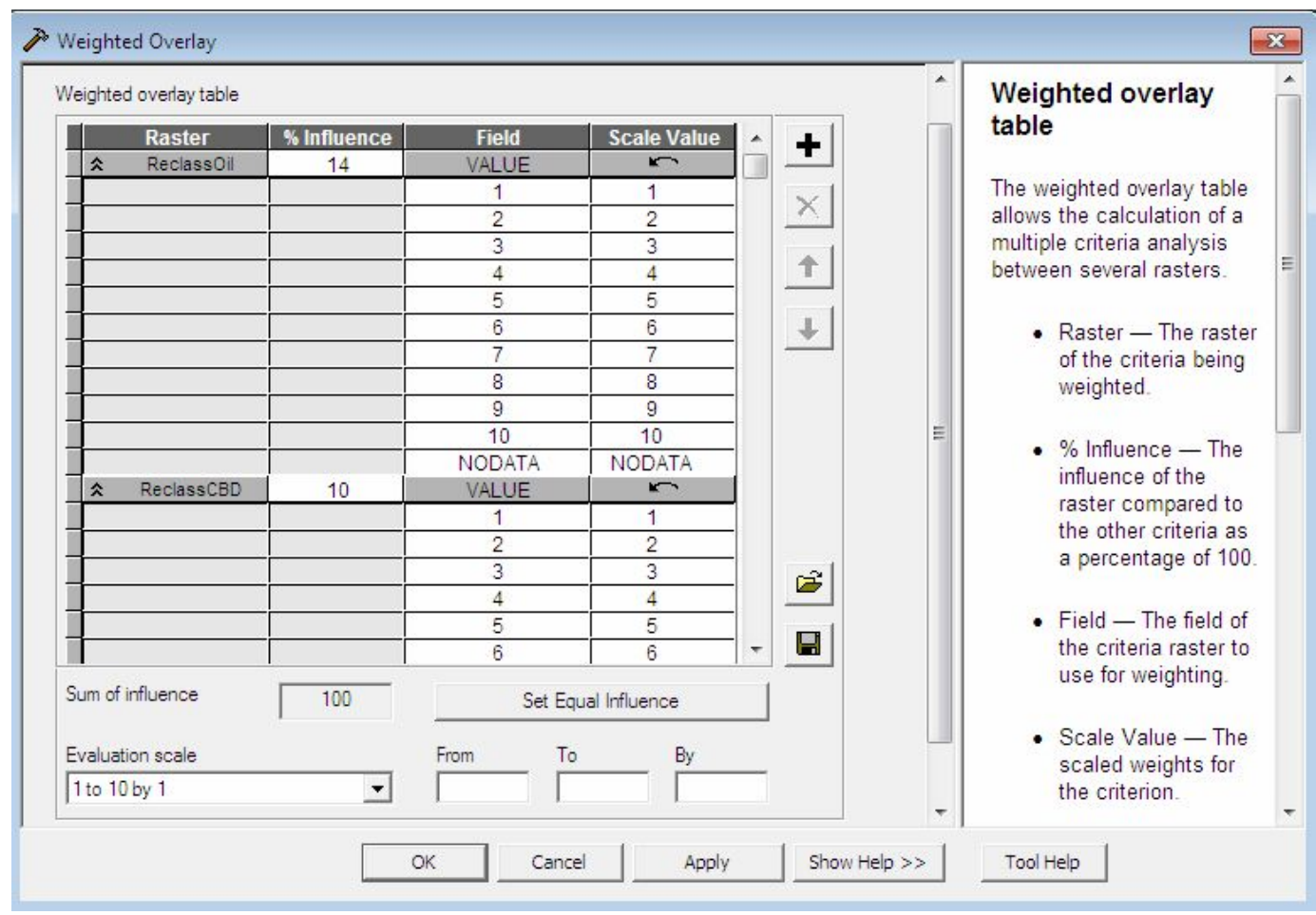

وبعد اعطاء الاوزان كما في الجدول ظهرت نتيجة الملاعمة المكانية واجراء عملية الفصل لكل نوع من انواع المناطق حسب درجة ملائكتها وعمل مسح للمناطق المتداخلة بين الطبقات كما مبينة في النموذج الهيكلي لكل العمليات الموضح في المخطط (Y) ، ظهرت النتائج كما مبينة في الخارطة 


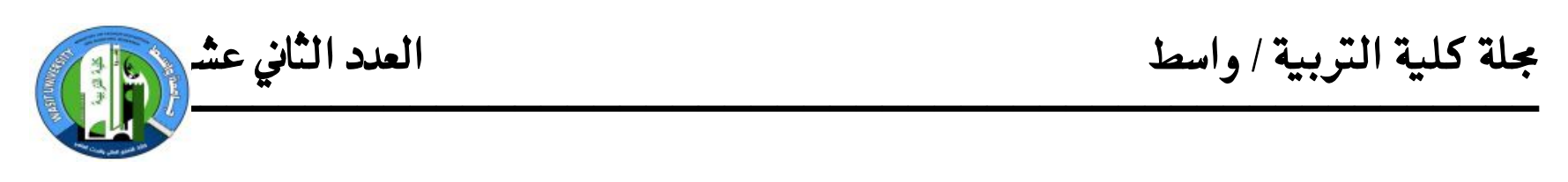

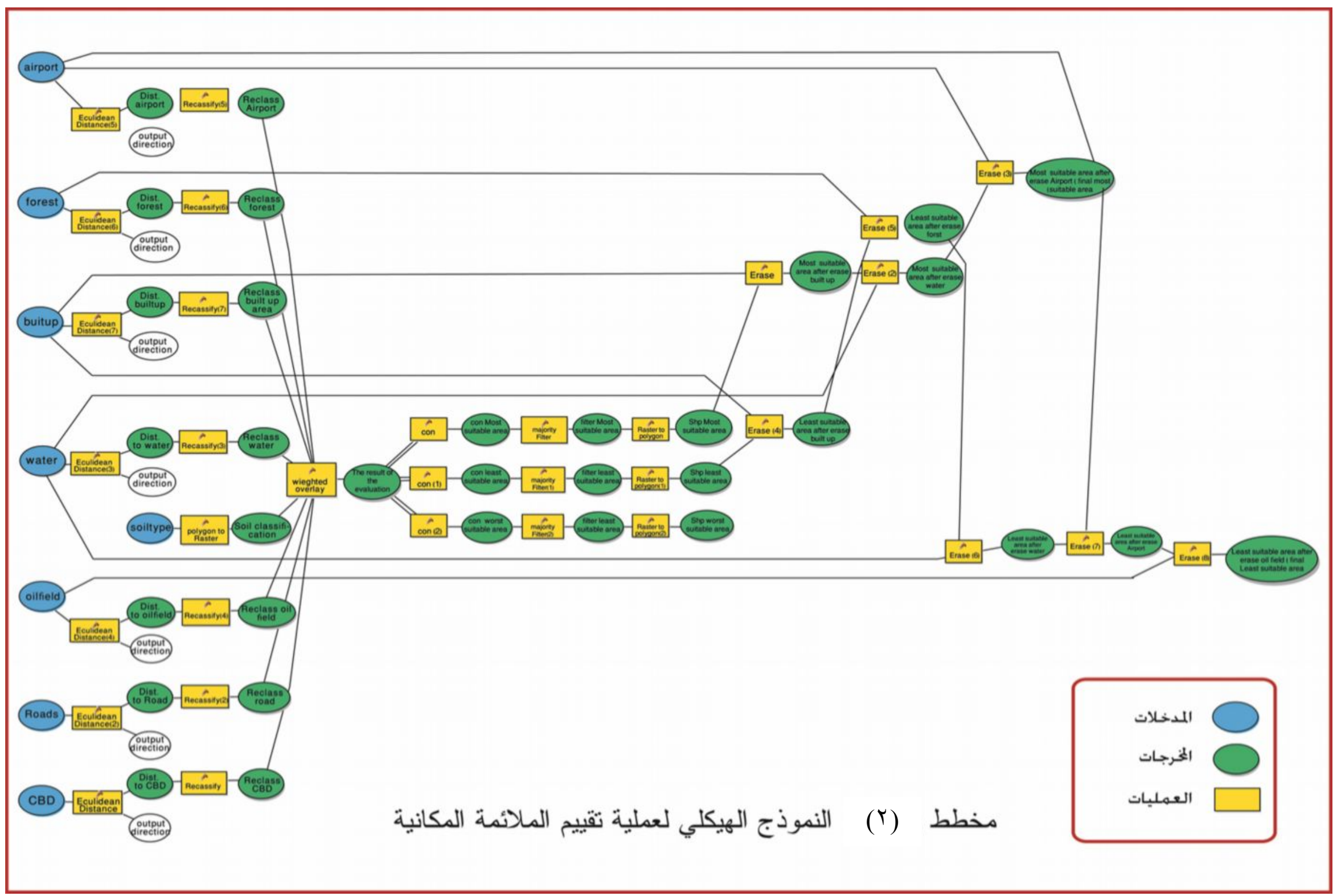




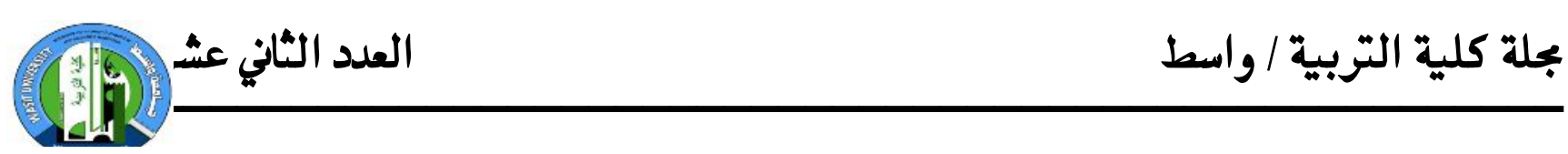

خارطة (· )

نتيجة الملاثمة المكاتية للتوسع بعلية التطابق الموزون (Weighted Overlay)

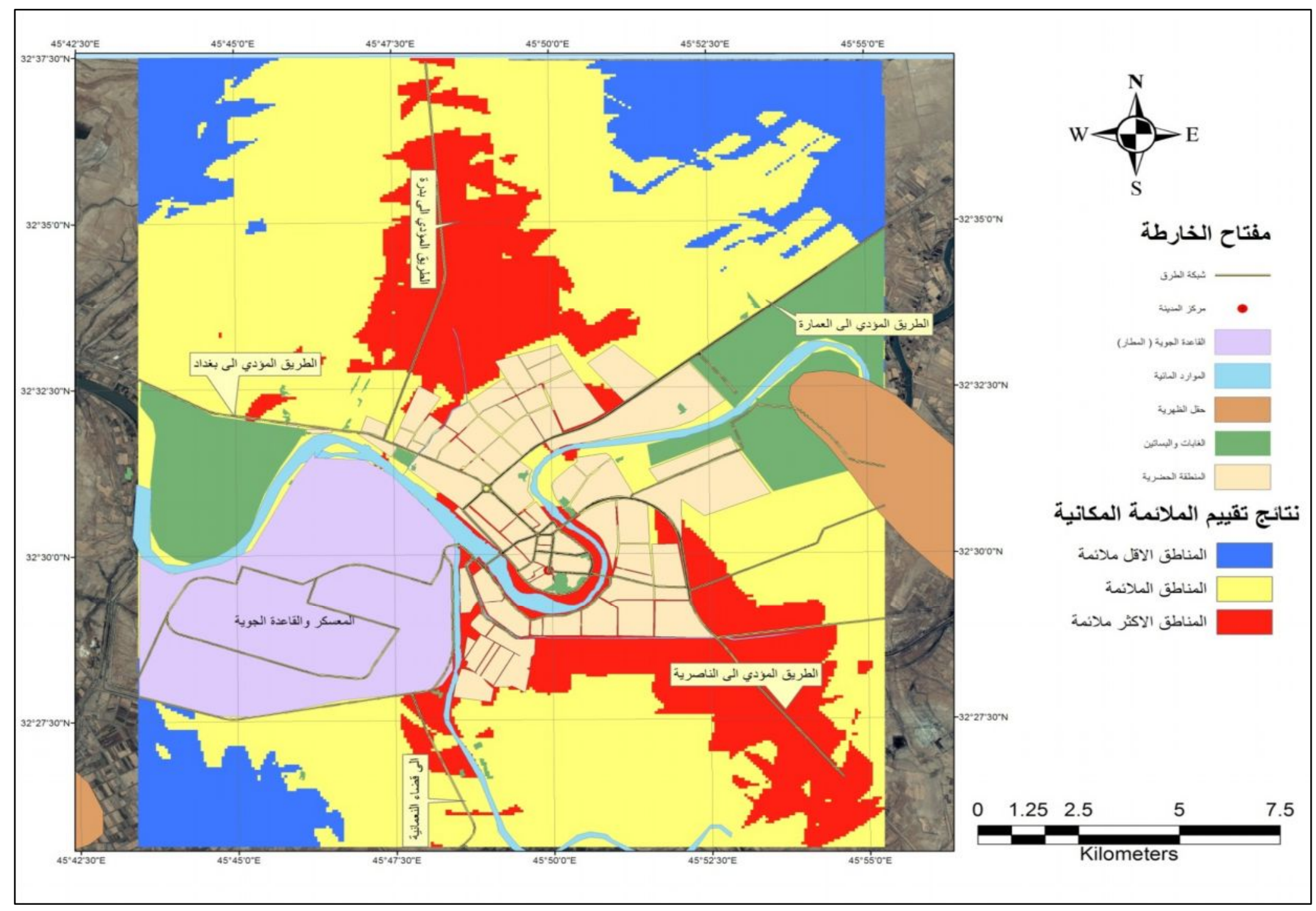


حيث تم بعد عملية التقييم عمل فصل للمناطق الناتجة بو اسطة الامر ( Conditon) ، وبعد ذلك

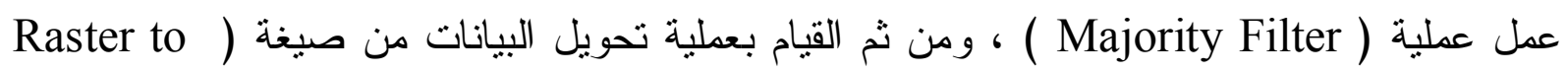
polygon لغرض معرفة المساحة الناتجة من عملية النقييم ، وعمل استثاء للمساحات الزائدة ، وقد

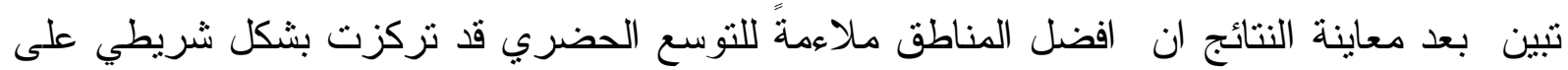
طريق (بدرة - الكوت ) ، وبشكل تجميعي في الحدود البلدية الثمالية وكذلك على طول المحور

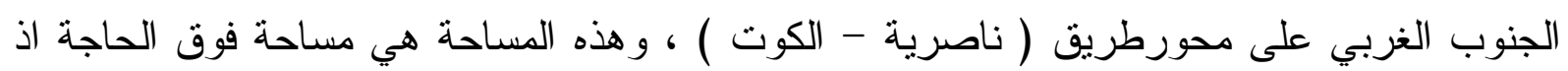

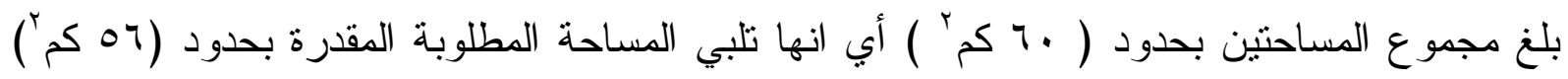

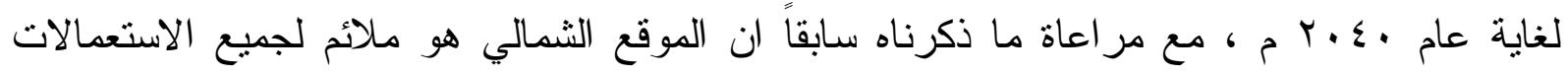

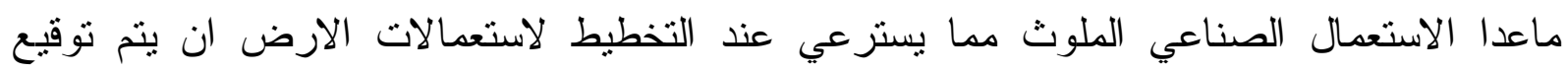

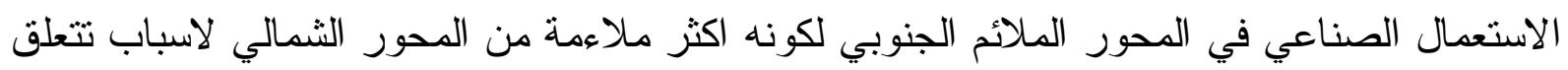

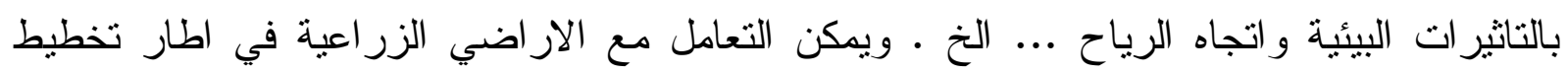

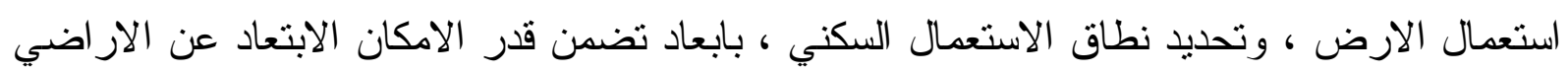

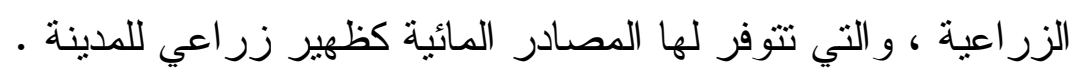

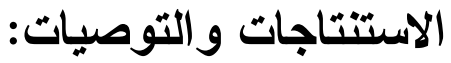

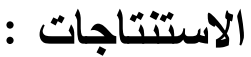

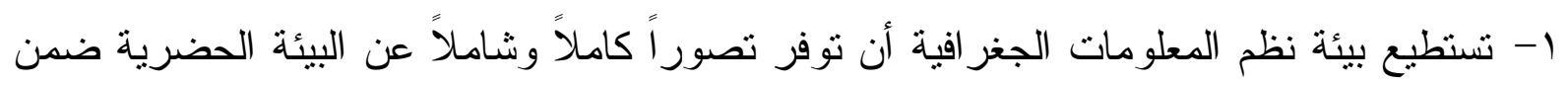
المدينة و اقليمها ، و هي بذلك تستطيع ان تعطي المؤشر ات الكافية في التوقيع المكاني للفعاليات المختلفة ، وكذلك من المكن ان نساهم في التوقيع المكاني للاستثمار ات في المستقبل .

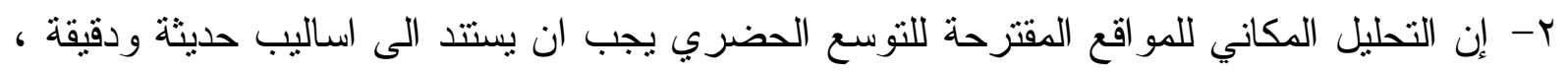

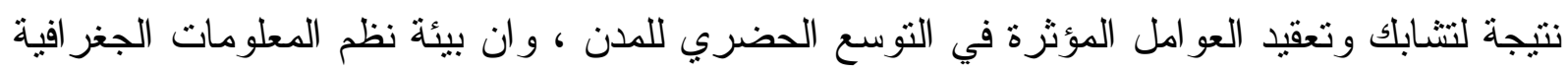

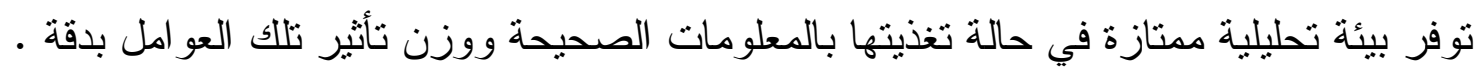

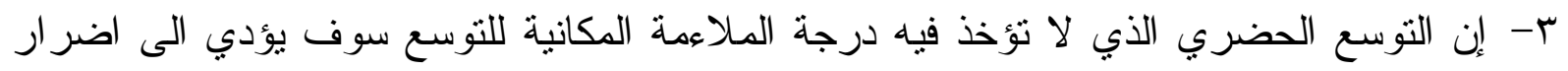

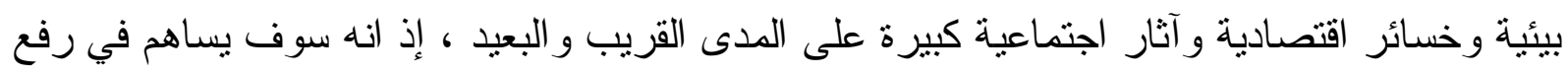

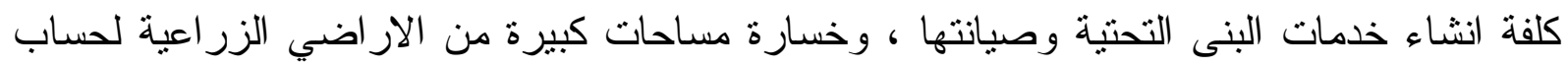

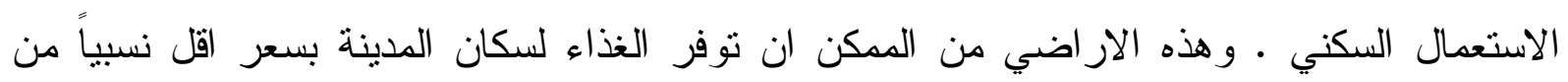

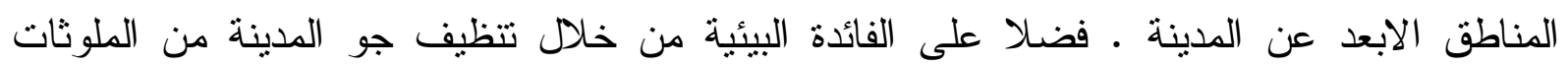
وحمايتها من التصحر وزحف الاعد عند الرمال . 
ع- إن أفضل المحاور للتوسع الحضري على وفق المنهجية والاسلوب المتبع في التحليل قد ظهرت على طول محور طريق بدرة-الكوت وبشكل تجميعي محاذي للامنداد الثمالي للحدود البلدية و المحور الآخر المفضل في الجهة الجنوبية الغربية على طريق كوت - ناصرية ، حيث يعد هذان المحوران

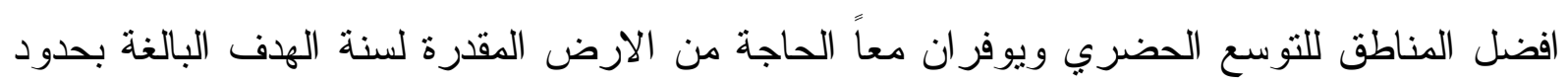
$\cdot(r$ S 04$)$

0- التوقيع المكاني الخاطئ لبعض الاستعمالات كالاستعمال العسكري المتمنل بوجود القاعدة الجوية

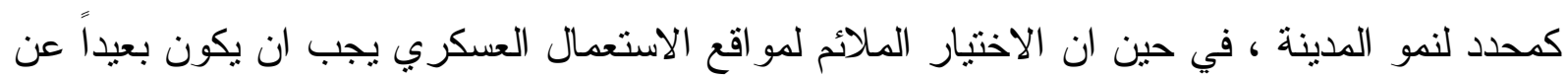

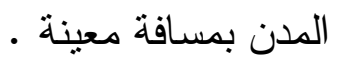

ج- ان مدينة الكوت قد عانت النوسع العشوائي غير المُخطَّط الذي لم يأخذ بعين الاهتمام الملاءمة المكانية للتوسع الحضري ، فثهدت التجاوز على الاراضي الزراعية الخصبة وتحويل استعمالها الى لى لئي السكني في ظل انعدام سلطة القانون • وتعد هذه الار اضي من المو ارد المهمة التي يجب الحفاظ عليها لكونها تزود المدينة بالغذاء اللازم (ظهير زراعي مهم للمدينة ). وان التجاوز على الاراضي الزر اعية سوف يؤدي الى فقدان الغطاء النباتي الذي يعمل على تحسين بيئة المدينة وتلطيف اجو اء المدينة ، و ان الاستمرار بالتجاوز عليه سوف يجعل المدينة عرضة الى التلوث نتيجة لاستتزاف الغطاء النباتي

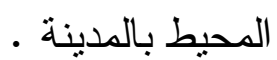

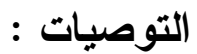

1- اعتماد المحورين الثمالي ، و الجنوبي الغربي بوصفهما أفضل المحاور لتوسع المدينة ونموها نسبة للعو امل المؤثرة التي نتجت من التحليل المكاني .

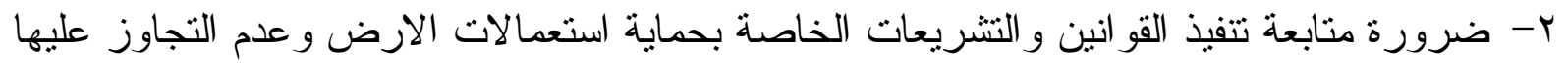

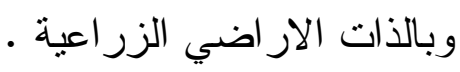

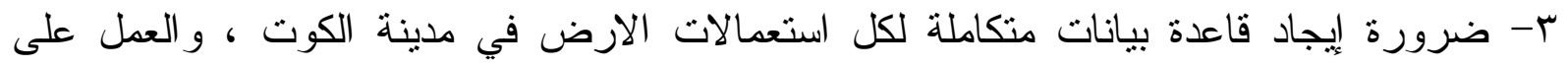

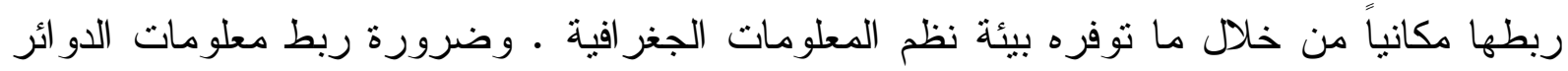

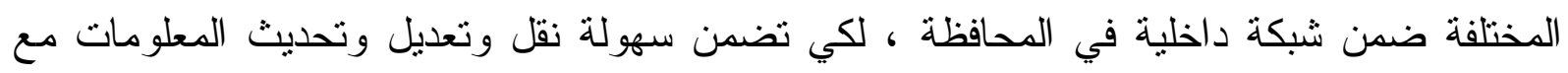

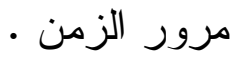
ع- عدم توقيع الاستعمالات الصناعية ضمن المحور الثمالي ، ونوقيعها ضمن المحور الجنوبي 
- - الاستفادة من التطبيقات المختلفة التي توفرها بيئة نظم المعلومات الجغر افية في دراسة التوقيع المكاني الافضل للاستعمالات المختلفة وفي رسم شبكة الطرق في التوسعات المستقبلية ـ وفي عملية اختيار أنسب المواقع المقترحة لامتدادات التجمعات القائمة، نظرًا لسهوله تطبيقها ودقة نتائجها، أذ يمكن الاستفادة من المنهج المقترح في عملية التطبيق للوصول إلى الأهداف المرجوة من تتمية هذه الامتدادات.

צ- ضرورة وضع مخطط عام فعال وشامل للمدينة ككل يتم فيه إتباع سياسة فعالة مرنة وموجهة من قبل السلطات المحلية و البلدية و العمل على تقييم مرحلي لعملية التتمية الحضرية كل مدة (0) سنوات لمر اقبة التوسع الحضري و اتجاهاته فيما لو كانت وفق ماهو مخطط لها او شهدت انحر افاً لكي يتم العمل على تصحيح المسار . المصادر : (1) n

1-الجنابي ، صلاح حميد ، "جغرافية الحضر، اسس وتطبقات"، مديرية دار الكتب للطباعة و النشر ، جامعة الموصل،

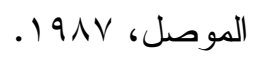

ץ-شرف ، محمد ابر اهيم محمد ، " التحليل المكاني باستخدام نظم المعلومات الجغرافية " ، دار المعرفة الجامعية

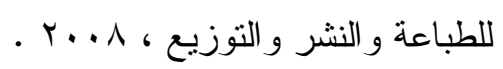

ب-عبد الحميد، محمد عبد العزيز و المسيند ، مساعد عبداله، "تطيق منهية التحليل المكاني باستخدام نظم

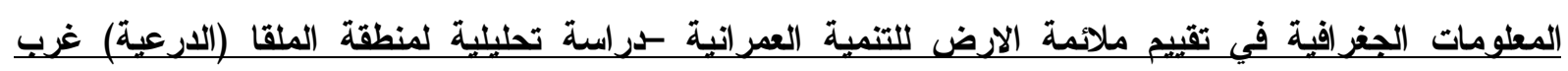

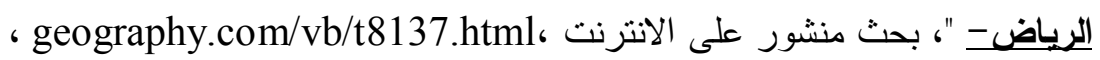

ع - غنيم ،محد عثمان \& ماجد ابو زنط ،"التنمبة المستدامة - فلسفتها واساليب تخطيطيها وادوات قياسها " ، دار

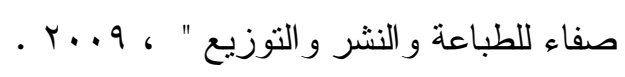
ه- الوكيل ، شفق العوضي ،" التخطيط العمر اني - مبادئ- (سس - تطيقات (الجزء الاول)" ، طا ،ج . . ب.

6- Anselin, L., "Exploratory Spatial Data Analysis and Geographic Information Systems ",A New Tools For Spatial Analysis, Luxembourg. 1994.

7- FAO , " A framework for land evaluation " Published by arrangement with the FAO of the united nations 1976.

8- Rossiter , D. G. ," A theoretical framework for land evaluation." geoderma 72 , . (1996)

9- YUAN LI , "Planning support for urban spatial development - A Case Study of Zhenning County- "Thesis submitted to the International Institute for Geo-information Science and Earth Observation, NETHERLANDS , 2003. 